Running title: Mediterranean rocky reefs in the Anthropocene

\title{
Mediterranean rocky reefs in the Anthropocene: present status and future concerns
}

Stanislao Bevilacqua ${ }^{1,22, *}$, Laura Airoldi ${ }^{2}$, Enric Ballesteros ${ }^{3}$, Lisandro Benedetti-Cecchi ${ }^{4,22}$,

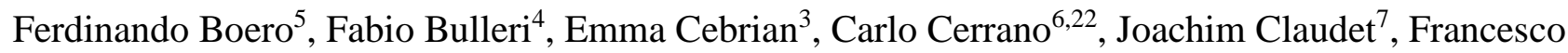
Colloca $^{8}$, Martina Coppari ${ }^{6}$, Antonio Di Franco ${ }^{9}$, Simonetta Fraschetti ${ }^{5,10,22}$, Joaquim Garrabou ${ }^{11,12}$, Giuseppe Guarnieri ${ }^{13,22}$, Cristiana Guerranti ${ }^{1}$, Paolo Guidetti ${ }^{14,13}$, Benjamin S. Halpern ${ }^{16}$, Stelios Katsanevakis $^{17}$, Maria Cristina Mangano ${ }^{9}$, Fiorenza Micheli ${ }^{18}$, Marco Milazzo ${ }^{19,22}$, Antonio Pusceddu $^{20}$, Monia Renzi ${ }^{1,22}$, Gil Rilov $^{21}$, Gianluca Sarà ${ }^{19}$, Antonio Terlizzi $^{1,10,22}$

${ }^{1}$ Dipartimento di Scienze della Vita, University of Trieste, Trieste, Italy

${ }^{2}$ Dipartimento di Biologia, University of Padova, Padova, Italy

${ }^{3}$ Centre d'Estudis Avançats de Blanes - CSIC, Girona, Spain

${ }^{4}$ Dipartimento di Biologia, University of Pisa, Pisa, Italy

${ }^{5}$ Dipartimento di Biologia, University of Napoli Federico II, Napoli, Italy

${ }^{6}$ Dipartimento di Scienze della Vita e dell'Ambiente, Polytechnic University of Marche, Ancona, Italy

${ }^{7}$ National Center for Scientific Research, PSL Université Paris, CRIOBE, USR 3278 CNRS-EPHE-UPVD, Maison des Océans, Paris, France

${ }^{8}$ Department of Integrative Ecology, Stazione Zoologica A. Dohrn - National Institute of Marine Biology, Ecology and Biotechnology, Rome, Italy

${ }^{9}$ Department of Integrative Marine Ecology, Stazione Zoologica Anton Dohrn, Sicily, Palermo, Italy

${ }^{10}$ Stazione Zoologica Anton Dohrn, Naples, Italy

${ }^{11}$ Institut de Ciències del Mar, CSIC, Passeig Marítim de la Barceloneta 37-49, 08003 Barcelona, Spain

${ }^{12}$ Aix Marseille Univ, Université de Toulon, CNRS, IRD, MIO, Marseille, France

${ }^{13}$ Dipartimento di Scienze e Tecnologie Biologiche ed Ambientali, University of Salento, Lecce, Italy

${ }^{14}$ Department of Integrative Marine Ecology, Stazione Zoologica A. Dohrn - National Institute of Marine Biology, Ecology and Biotechnology, Naples, Italy. 
${ }^{15}$ National Research Council, Institute for the Study of Anthropic Impact and Sustainability in the Marine Environment (CNR-IAS), Genoa, Italy.

${ }^{16}$ National Center for Ecological Analysis \& Synthesis, University of California, Santa Barbara, CA, USA

${ }^{17}$ Department of Marine Sciences, University of the Aegean, Mytilene, Greece

${ }^{18}$ Hopkins Marine Station and Center for Ocean Solutions, Stanford University, Pacific Grove, CA, USA

${ }^{19}$ Dipartimento di Scienze della Terra e del Mare, University of Palermo, Palermo, Italy

${ }^{20}$ Dipartimento di Scienze della Vita e dell'Ambiente, University of Cagliari, Cagliari, Italy

${ }^{21}$ National Institute of Oceanography, Israel Oceanographic and Limnological Research, Haifa, Israel

${ }^{22}$ Consorzio Nazionale Interuniversitario per le Scienze del Mare, Rome, Italy

*Corresponding author:

Stanislao Bevilacqua

Dipartimento di Scienze della Vita, Università di Trieste - CoNISMa

Via Licio Giorgieri, 10 - 34127 Trieste (Italy)

Email: sbevilacqua@units.it

Tel. | Ph. +390405588833

Cell. | Mob. +39 3397418131

\section{Author contribution}

SB outlined and led the manuscript drafting. All authors equally contributed to intellectual contents, writing and critical review of the manuscript. 


\begin{abstract}
Global change is striking harder and faster in the Mediterranean Sea than elsewhere, where high levels of human pressure and proneness to climate change interact in modifying the structure and disrupting regulative mechanisms of marine ecosystems. Rocky reefs are particularly exposed to such environmental changes with ongoing trends of degradation being impressive. Due to the variety of habitat types and associated marine biodiversity, rocky reefs are critical for the functioning of marine ecosystems, and their decline could profoundly affect the provision of essential goods and services which human populations in coastal areas rely upon. Here, we provide an up-to-date overview of the status of rocky reefs, trends in human-driven changes undermining their integrity, and current and upcoming management and conservation strategies, attempting a projection on what could be the future of this essential component of Mediterranean marine ecosystems.
\end{abstract}

Key-words: algal forests, bioconstructions, coastal ecosystems, conservation, fish assemblages, global change, marine biodiversity 


\section{Contents}

1. Introduction

2. Mediterranean rocky reef communities: structure and dynamics

2.1. Patterns and processes in benthic assemblages

2.1.1. Mediolittoral and infralittoral zone

2.1.2. Circalittoral zone

2.2. The role of fish

2.3. The contribution of rocky reefs to coastal ecosystem functioning and services

3. Human threats to Mediterranean reefs: status and trends

3.1. Pollution

3.2. Direct physical habitat disruption and artificialisation

3.3. Overfishing

3.4. Bioinvasions

3.5. Climate change

3.6. Cumulative human pressure

4. Achievements and next targets for reef conservation

4.1. Current conservation measures

4.2. Future conservation needs

4.3. Frontiers in the restoration of rocky habitats

5. Next challenges and perspectives in ecological research

6. The fate of Mediterranean rocky reefs 


\section{Introduction}

The unprecedented anthropogenic modifications of the global environment are leading the planet towards uncharted conditions, with the risk of crossing safe operating boundaries beyond which undesirable, and probably abrupt, ecological shifts could pose serious concerns about the future of our society (Steffen et al., 2015). The pace of increasing human impact is particularly alarming for seas and oceans (Halpern et al., 2019), especially in coastal areas, where human activities and populations concentrate and the current emphasis for blue economy might, indeed, ultimately harm marine ecosystems (Bennett et al., 2019).

Reef habitats are highly sensitive to global change and have undergone a drastic deterioration worldwide, which still continues without signs of slowing down (Hughes et al., 2010; Krumhansl et al., 2016). They are among the most productive and diverse marine environments, largely contributing to the functioning of much wider ecosystems that comprise vast volumes of marine space (Boero et al., 2019) and are, therefore, crucial for the provision of goods and services by the ocean.

In the Mediterranean Sea, hard bottoms are of paramount ecological importance for coastal ecosystems. More than half of the shores are rocky (Furlani et al., 2014) and biogenic hard substrates may extend for hundreds of thousands hectares in shelf areas (Martin et al., 2014). The variety of coastal rocky habitats is extremely high, spanning from the mediolittoral to the infralittoral and circalittoral zone, and comprising macroalgal and animal forests, rock beds and cliffs, submarine caves, and several types of bioconstructions (Fig. 1) that, along with seagrass beds, host most of the vast and endemism-rich Mediterranean marine biodiversity (Ballesteros, 2006; Coll et al., 2010; Ingrosso et al., 2018). Their complexity and the associated species, phylogenetic, and functional diversity place rocky reefs among the habitats that are often represented within Marine Protected Areas (MPAs) (Agnesi et al., 2020). However, shoreline and nearshore reefs are experiencing a widespread degradation over the entire basin (Sala et al., 2012; 
Bevilacqua et al., 2020), so that the ecological condition of $1 / 3$ to $2 / 3$ of them might be classified as moderate to poor (Bevilacqua et al., 2020).

Understanding causes and mechanisms underlying this trend and the ensuing detrimental effects on the integrity of marine ecosystems is critical to develop future strategies that could counteract the ongoing degradation, and to build socioeconomic resilience (Branch et al., 2008; Rilov et al., 2019a). In this chapter, we attempted to synthesize current information on diversity, structure and functioning of Mediterranean rocky reef ecosystems, the main human threats, and the potential implications for their integrity and persistence. We also provided an up-to-date overview of present and forthcoming conservation measures, current research needs and potential future avenues, trying to envisage what could be the fate of Mediterranean rocky reefs in the coming years.

\section{Mediterranean rocky reef communities: structure and dynamics}

\subsection{Patterns and processes in benthic assemblages}

\subsubsection{Mediolittoral and infralittoral zone}

The Mediterranean Sea should be classified somewhere between a subtropical (mostly the southeast basin) and a temperate sea (mostly the western basin). The seasonal variability in temperature, light availability and dissolved nutrient concentrations are similar to temperate environments but the average values are closer to subtropical seas. These features hinder the development of kelps and hermatypic corals (Zabala and Ballesteros, 1989), which, although present in the Mediterranean (i.e., Laminaria rodriguezii, Cladocora caespitosa), have a limited occurrence. Instead, rocky reefs where light intensity allows supporting photosynthetic growth are characterized by a large diversity of erect, turf, and encrusting algae (Rodríguez-Prieto et al., 2013).

In a sea where tidal ranges are extremely small (except for the Alboran Sea and the northern Adriatic), the wide intertidal assemblages characterizing most oceanic rocky shores are almost 
absent with several mediolittoral assemblages alternating at different levels of the shore, usually arranged in very narrow belts. The upper mediolittoral is dominated by barnacles and littorinids, whereas the lower levels show belts of different species of erect and encrusting algae (Chappuis et al., 2014). In strongly exposed sites of the northern Mediterranean, the massive coralline alga Lithophyllum byssoides can produce hard calcareous concretions called "trottoirs" (Fig. 1) which form rims over the sea level. The lower part of the mediolittoral fringe is occupied by erect and turf red algae, but mussels (Mytilus galloprovincialis) and green algae (Cladophora spp., Ulva spp.) thrive in nutrient-rich environments (Rodríguez-Prieto et al., 2013). In the warmest regions, gregarious vermetid gastropods form dense aggregations cemented by the encrusting coralline alga Neogoniolithon brassica-florida, favouring the development of conspicuous platforms on subhorizontal surfaces, hosting diverse macroalgal assemblages (Fig. 1) (Rilov et al., 2020a). The horizontal to almost vertical rocky bottoms in the infralittoral zone are dominated by macroalgae, although extensive meadows of seagrass Posidonia oceanica can also be found on shallow horizontal hard substrates (Rodríguez-Prieto et al., 2013). At the upper infralittoral level, belts of Fucales (Ericaria, Gongolaria, Cystoseira, Sargassum) develop both in exposed and sheltered areas (Fig. 1). The eastern Mediterranean also hosts concretions of coralline algae Tenarea tortuosa and Titanoderma trochanter in the shallows. In areas below $2 \mathrm{~m}$ depth, photophilic assemblages composed mostly by Sphacelariales, Dictyotales, Gigartinales or Bryopsidales are extremely common, although the best preserved sites are usually occupied by stands of Fucales (Rodríguez-Prieto et al., 2013). In the Alboran Sea and the Strait of Messina, Saccorhiza polyschides (Tylopteridales) makes luxurious underwater beds (Giaccone, 1972).

An interesting feature of Mediterranean macroalgal stands is their high biodiversity associated to a high miniaturization (Coppejans, 1980); more than one hundred different algal species can coexist in a small surface not larger than a sheet of paper $\left(600 \mathrm{~cm}^{2}\right)$. This means that the so-called Mediterranean marine forests dominated by Fucales are miniaturized representatives of the huge 
oceanic temperate forests of Laminariales, with canopies not exceeding 20 to $40 \mathrm{~cm}$ but with a similar structural complexity. The complex three-dimensional structure of such canopies allows very speciose animal assemblages to develop in the understory or as epiphytes, whose diversity and distribution is strongly influenced by spatio-temporal variations of macroalgal stands (Fraschetti et al., 2006; Piazzi et al., 2018).

Most Mediterranean shallow macroalgal assemblages show a marked seasonality. In the mediolittoral zone, midwinter is the period of maximum growth, with the maximum development showing up from early spring to midsummer (Ballesteros, 1991). In autumn and early winter, Mediterranean vegetation is usually in a resting phase, although invasive species such as Lophocladia lallemandii, Womersleyella setacea or Caulerpa cylindracea can attain high growth rates and biomass in autumn. Measured average yearly production reaches $900 \mathrm{~g} \mathrm{C} \mathrm{m}^{-2}$ year $^{-1}$ in the upper part of the infralittoral fringe from exposed environments with dense populations of Fucales, whereas figures around 100-300 $\mathrm{g} \mathrm{C} \mathrm{m}^{-2}$ year $^{-1}$ are common in infralittoral communities with canopy-forming algae (Ballesteros, 1989).

Aside from anthropogenic drivers (see section 3), the spatial distribution of macroalgae and associated invertebrate assemblages reflects a combination of different bottom-up and top-down processes (Hereu et al., 2008). The distribution of different species of Fucales along the depth gradient mainly depends on each species' photosynthetic efficiency (Sant and Ballesteros, 2021), whereas the interplay among changes in vegetation, life cycles, feeding habits and competitive abilities shape species composition and abundances of invertebrate assemblages (e.g., Terlizzi et al., 2003). Biomineralogy plays an important role in community assembly, influencing settlement and recruitment processes of different species associated with rocky reefs, from algae to fishes, depending on rocky lithology (Guidetti et al., 2004). Other factors, such as regimes of exposure to air and nutrient availability are pivotal for mediolittoral and upper infralittoral assemblages respectively. Catastrophic events such as huge storms or thermal anomalies also regularly shape 
shallow assemblages (e.g., Navarro et al., 2011; Verdura et al., 2021). Amongst top-down

processes, overgrazing by sea urchins such as Paracentrotus lividus and Arbacia lixula (but also by herbivorous fishes, see paragraph 2.2), could strongly reduce algal biomass, availability and export of algal detritus, and simplify the associated community structure (Sala et al., 1998; Sala et al., 2012; Yeruham et al., 2020).

\subsubsection{Circalittoral zone}

Although extremely limited geographically, most impressive algal beds in the circalittoral zone are those with kelp Laminaria ochroleuca from the Alboran Sea and the Strait of Messina (Giaccone, 1972). Much more widespread are other canopy-forming algal assemblages dominated by Fucales, Dictyotales, Sphacelariales, Ceramiales or Gigartinales (Rodríguez-Prieto et al., 2013). Worth mentioning are the assemblages dominated by the endemic kelp Laminaria rodriguezii in eastern Mediterranean and the Adriatic Sea, which can be found down to almost $100 \mathrm{~m}$ depth (Žuljević et al., 2016). Erect members of the order Bryopsidales and Peyssonneliales are usually dominant in the upper circalittoral zone but a huge number of red algae are also common and characteristic of these environments (UNEP-RAC/SPA, 2003).

The most widespread Mediterranean deep-water macroalgal assemblages are coralligenous outcrops, biogenic reefs built by calcareous algae of the genus Lithophyllum, Mesophyllum, Neogoniolithon, Lithothamnion and Peyssonnelia (Ballesteros, 2006). Above the basal layer made by calcareous algae, a rich flora and fauna develop, ranking the coralligenous bioconstructions amongst the most biodiverse assemblages in the Mediterranean Sea, with a rough estimate of species richness being far above 1500 species (Ballesteros, 2006). These bioconstructions, which are made by living benthic organisms that overgrow the calcareous remnants of previous generations, change the primary geological substrate creating a secondary biogenic hard substrate, representing a preferred habitat for the settlement, spawning, recruitment, feeding and shelter of a 
wide variety of marine species. The habitat provision through bioconstruction can be mediated by either vegetal (e.g., coralline algae, coralligenous sensu stricto) (Ingrosso et al., 2018) and/or animal organisms such as corals, sponges, bryozoans, molluscs and polychaetes among others (Corriero et al., 2019; Cardone et al., 2020). The general pattern of coralligenous allows to recognize four main levels of organization due to i) cryptic/boring, ii) encrusting, iii) massive, and iv) arborescent organisms (Fig. 2A).

In coralligenous bioconstruction (Fig. 2Bv), the three-dimensional complexity created by both boring and erect organisms influences the biodiversity of vagile benthic fauna with gastropods, polychaetes, crustaceans, echinoderms, and fishes representing the most common vagile organisms inhabiting bioconcretions (Ballesteros, 2006; Valisano et al., 2016). When the primary geological substrate is granitic, volcanic or not calcareous, the contribution of bioeroders is limited; epilithic coralline algae and calcified animals show lower capability to build thick concretions on granite compared to limestone (Canessa et al., 2020). In this case, the bioconstruction can be very limited (Fig. 2Bvii) and the general structure of the community is less complex, confirming the pivotal role of biomineralogy in structuring benthic assemblages (Bavestrello et al., 2000). Recently, a new type of bioconstruction has been described along the Italian coast of Apulia (Cardone et al., 2020). Main builders of this bioconstruction are scleractinians and the bivalve Neopycnodonte cochlear, which make mass aggregations on the sea bottom on both soft and hard substrates, supporting the development of a rich benthic associated fauna (Fig. 2Bvi).

Light availability drives the dynamics of circalittoral assemblages, mediating the depth distribution of the algal components (Sant and Ballesteros, 2021). Seasonality is also important in determining temporal variations of macroalgae in the circalittoral zone, with the period of maximum growth ranging between late spring and early summer (Ballesteros, 1991) and average yearly production ranges from 30-150 $\mathrm{g} \mathrm{C} \mathrm{m}^{-2}$ year $^{-1}$ in upper circalittoral coralligenous environments (Ballesteros, 1989; UNEP-RAC/SPA, 2003). Competition for food and space is the main process affecting 
species distribution and abundance, the species being forced to develop a highly specialized diet and niche to coexist in the same habitat (Morganti et al., 2017). However, cooperation among species is common, with some species facilitating the settlement of others (Gribben et al., 2019). In the absence of human impacts, the development of slow-growing and long-living species, especially sponges and anthozoans is favoured (Montero-Serra et al., 2018), mediating long-term stability conditions (Cerrano et al., 2010; 2019). Stability and longevity enhance intra and inter-specific interactions facilitating coevolutionary pathways, which, in turn, further contribute to the persistence of the ecosystem itself (Pola et al., 2020).

\subsection{The role of fish}

Out of the approximately 650 fish species inhabiting the Mediterranean Sea, rocky reefs host about 200 species belonging to 40 families, covering a wide range of trophic levels (Sala et al., 2012; Guidetti et al., 2014; Bussotti et al., 2015). Species richness has been suggested to be driven by biogeographic patterns with the highest values recorded between $10^{\circ}-20^{\circ} \mathrm{E}$ longitude (Guidetti et al., 2014), and be positively correlated with depth (Harmelin-Vivien et al., 2005). The highly diversified fish assemblages of Mediterranean rocky reefs support a large variety of ecological traits and functions (Albouy et al., 2015).

Rocky reef fish act as trophic vectors connecting different Mediterranean habitats. This is the case of small-sized and gregarious fish like the widespread damselfish Chromis chromis and the cardinal fish Apogon imberbis, whose nycthemeral migrations between the water column and the bottom and in/out of marine caves, transfer organic matter - mostly via faecal pellets - into depleted rocky reef habitats (Pinnegar and Polunin, 2005; Bussotti et al., 2018).

High-level predator fishes exert top-down controls triggering trophic cascades directly and indirectly affecting a large number of species, finally shaping the structure and functioning of the entire coastal rocky ecosystems (Prato et al., 2013). These large-sized and long living animals, like 
as sharks and groupers, nowadays are generally depleted in the Mediterranean Sea due to overfishing. The reduction in populations of high-level predators has determined the disruption of the ecological functions that these species perform especially in shallow rocky habitats. Here, the decreased functional redundancy at high trophic levels has left medium-sized fish like seabreams alone to control ecosystem structure by regulating the grazing pressure exerted by sea urchins on erect macroalgae, increasing the chance of drastic shifts in coastal ecosystems (see paragraph 3.3). Contrary to what has been thought until a decade ago, even the very few macro-herbivorous fish species present in the Mediterranean Sea heavily contribute to regulating the functioning of shallow rocky ecosystems (Sala et al., 2011). Both the native salema Sarpa salpa, widely distributed in the western Mediterranean, and the invasive rabbitfishes Siganus luridus and S. rivulatus, that entered via the Suez Canal between 1927 and 1956 and more recently replacing the native salema in the eastern Mediterranean, may represent a threat to macroalgal canopies and indirectly to the high diversity they support (Verges et al., 2014; Gianni et al., 2017, Rilov et al., 2018).

In this regard, a more general reshuffling of the Mediterranean reef fish assemblages has occurred in the last few decades. This was mainly attributed to changes in the relative abundances of native species as a result of geographical range contractions and deepening of cool-water fishes, rapid range extensions of alien warm-water and tropical fishes, and changing interspecific interactions (Milazzo et al., 2013; Azzurro et al., 2019). Model projections suggest a dramatic reduction of Mediterranean endemic fish by the end of this century (Ben Rais Lasram et al., 2010).

\subsection{The contribution of rocky reefs to coastal ecosystem functioning and services}

Mediterranean rocky reefs, from the shore to shelf areas, are highly dynamic, in both time and space, and productive systems. They receive abiotic and biotic inputs from both the open sea and the mainland, through water mass movements that locally may have seasonal fluctuations and that are able to connect adjacent ecosystems. Ecological connectivity can be very high at a regional 
scale (Rattray et al., 2016; Bevilacqua and Terlizzi, 2020) being the outcome of community assembly processes, which are mainly driven by the local species pools (Briton et al., 2018). However, spatial patterns of compositional and functional diversity in Mediterranean rocky reefs can overlap or diverge due to the complex interplay among functional redundancy of species, environmental filtering and biogeography (Bevilacqua and Terlizzi, 2020). Due to their high habitat heterogeneity and diversity, which offer a variety of niches available from the upper mediolittoral to the deeper circalittoral habitats, the biological components of the Mediterranean rocky reefs express a lot of different ecological functions (de la Torriente et al., 2020).

The large variety of rocky reef species and the associated functional traits is responsible for a range of benefits to humans in terms of ecosystem services, which are at the base of the human wellbeing of most Mediterranean coastal countries. For example, despite the mediolittoral being limited to a few tens of centimetres, assemblages in this zone play a fundamental role in the overall functioning of coastal ecosystems. Trottoirs formed by vermetid platforms, distributed across the warmest coastlines of the basin, provide several ecosystem services associated with production functions (e.g., the provision of food and baits), to regulation functions by influencing water column quality (e.g., filtering) and enhancing anthropogenic disturbance prevention, to support functions, through the provision of food and organisms to adjacent systems, and to cultural functions, by offering space for recreation/leisure, exploration and relaxation (Milanese et al., 2011). In the lower mediolittoral fringe, and where trophic conditions are more enriched, mussel beds are mainly built by Mytilus galloprovincialis and represent a crucial element of the rocky shore biodiversity. Their local loss or reduction in density generates changes in the associated assemblages (Maggi et al., 2009) with a net loss of services such as water quality regulation, habitat and refugia, and enhancement of habitat heterogeneity.

At the other depth extreme, in the circalittoral zone, coralligenous habitats are so structured and biodiverse that are able to provide a number of ecosystem services (UNEP-RAC/SPA, 2003), from 
provisioning (e.g., food, red coral and species for aquariums), regulating (e.g., carbon sequestration and water filtration), cultural (e.g., recreational diving and intellectual/spiritual inspiration) to supporting (e.g., species nursery and refugia) services (de Ville d'Avray et al., 2019).

In the middle of these two depth extremes, in the infralittoral zone, vegetated rocky substrates certainly provide the most important contribution to the functioning of coastal ecosystems. They are primary sources and sinks of blue carbon, participate in nutrient cycling, provide essential support for marine coastal biota by providing food, nursery and shelter (Mineur et al., 2015; Zunino et al., 2020), and foster the diversity of important ecological compartments, such as microbiota and meiofauna (Bianchelli and Danovaro, 2020).

Recent attempts to quantify energy flows in Mediterranean algal forests and coralligenous outcrops revealed a prominent input of these habitats to the energetic budget of coastal ecosystems (De la Fuente et al., 2019a; Buonocore et al., 2020). Nonetheless, an accurate and synthetic evaluation of ecosystem services provided by rocky reefs across the Mediterranean Sea is still not addressed although it would be of paramount importance for decision-makers and environmental practitioners in order to set appropriate conservation and management measures.

\section{Human threats to Mediterranean reefs: status and trends}

Rocky reef assemblages have shown critical changes due to anthropogenic activities in most of the Mediterranean Sea (Claudet and Fraschetti, 2010; Rilov et al., 2018). The prevalent and widely reported modification concerns the structure of macroalgal stands, shifting from canopies to less complex communities dominated by turf or encrusting algae (e.g., Thibaut et al., 2015; Rilov et al., 2018). The ensuing reduction in primary production and habitat complexity largely turned into profound changes of the animal component of rocky reef assemblages (Peleg et al., 2020). Several benthic invertebrates and fish species of Mediterranean rocky reefs have also been threatened by a long history of intense exploitation. In some cases, such as for collection of commercial sponges 
and red coral, highly damaging fishing tools have been adopted in the last centuries (Cattaneo-Vietti et al., 2016), deeply altering the structure of benthic assemblages of many rocky reefs. However, one major driver of change cannot be unequivocally identified and most studies infer several interacting anthropogenic stressors in determining the ongoing alterations of reefs (Bevilacqua et al., 2018; Rilov et al., 2018), including pollution (Ivesa et al., 2016), urbanization (Mangialajo et al., 2008), destructive fishing (Rodríguez-Prieto et al., 2013), increase in sedimentation rates (Airoldi, 2003), overfishing (Sala et al., 1998; Sini et al., 2019), biological invasions and disease outbreaks (Sala et al., 2011; Vezzulli et al., 2013; Rilov et al., 2018).

In the last twenty years, the increase in intensity and frequency of thermal anomalies and extreme marine weather events is causing destructive disturbance episodes and mass mortalities, leading to very marked alterations of density and size of the epibenthic structuring species (Teixidó et al., 2013; Sarà et al., 2014; Garrabou et al., 2019), or mining their reproductive potential, and therefore, their persistence (Bevilacqua et al., 2019). Acidification may also deeply influence benthic assemblages, affecting the structural component represented by coralline algae and hard shelled invertebrates (Martin and Gattuso, 2009; Rastelli et al., 2020), thus altering the balance between bioconstruction and bioerosion processes of rocky reefs (Cerrano et al., 2001). Climate change, therefore, will exacerbate human impacts (Gissi et al., 2021; Verdura et al., 2021), with additive effects on the degradation of reef assemblages (e.g., Rilov et al., 2018; Peleg et al., 2020), further eroding their resilience potential.

\subsection{Pollution}

A closed basin like the Mediterranean Sea, which receives multiple inputs from the mainland, from maritime transportation and aquaculture, and has little turnover, is particularly exposed to pollution. On shallow rocky reefs, the emblematic outcome of organic and inorganic pollution from waste discharges is the proliferation of tolerant, opportunistic species, over sensitive, habitat-structuring 
species (e.g., Terlizzi et al., 2005), which in turn results in biodiversity loss of the understorey and associated fish assemblages (Azzurro et al., 2010). Cystoseira s.l. species and other habitat formers, like vermetids, can be particularly affected by surface pollutants such as hydrocarbons, surfactant detergents, and herbicide (Badreddine et al., 2019; de Caralt et al., 2020), suggesting that pollution could have contributed to their decline in the basin.

In the last years, although contamination levels in coastal areas have decreased, concerns on emerging pollutants have been raised, especially on plastic litter (UNEP/MAP, 2017). Marine litter has been found in the Mediterranean Sea in similar quantities to those observed in the five oceanic garbage patches (Fossi et al., 2020), and the presence of microplastic (i.e., fragment size $1 \mu \mathrm{m}-5$ $\mathrm{mm}$ ) has been widely documented throughout the basin (Martellini et al., 2018). The average concentration of microplastic in the water column in the Mediterranean Sea is $2.3 \mathrm{~kg} \mathrm{~km}^{-2}$, ranging between $6.5 \mathrm{~kg} \mathrm{~km}^{-2}$ and $1.5 \mathrm{~kg} \mathrm{~km}^{-2}$ (Soto-Navarro et al., 2020). Since many invertebrates on rocky reefs are suspension-filter feeders, the increasing amount of microplastics is particularly alarming due to their potential bioaccumulation, and biomagnification through the trophic web.

Several studies have suggested that microplastics can carry toxic chemicals, as well as microscopic organisms, that animals inadvertently swallow (e.g., van Der Hal et al., 2020). The transport of microplastics in the environment is accompanied by the immigration of contaminants (e.g., polychlorinated biphenyls, brominated flame retardants, polycyclic aromatic hydrocarbons, bisphenol A) via sorption/desorption, known as the "Trojan-Horse effect" (Zhang and Xu, 2020). This phenomenon significantly changes the potential health risks of microplastics by enhancing the bioavailability of contaminants for living organisms (Li et al., 2016). Also, many organisms, such as benthic diatoms and microalgae, adhere to the fragments and can be involuntarily swallowed causing also dietary alterations or the introduction of potentially pathogenic or toxic species (Cole et al., 2011). Microplastics are only one aspect of the problem, since plastic fragments smaller than microplastics, the so-called nanoplastics (i.e., fragment size 1-1000 nm), are likely to represent a 
more subtle hazard for marine organisms, since they can have a higher ability to adsorb and carry toxic compounds if compared to microplastics (Rios Mendoza et al., 2018; Piccardo et al., 2021).

Other emerging environmental pollutants for the marine environment are pharmaceutical residues, which have been detected in different marine organisms, from algae to bivalves, crustaceans and fish (Fabbri and Franzellitti, 2016; Almeida et al., 2020). These substances may interfere with subcellular and cellular processes of marine organisms, threatening the survival of the marine microbiota, with consequences that can potentially propagate to the highest levels of the trophic web, posing a health risk also for humans (Fabbri and Franzellitti, 2016).

The long-term effects that old and new pollutants could have on the marine environment are not yet fully understood, especially in light of potential synergies with other drivers of global change, increasing the uncertainty on future scenarios. Global warming and the ocean acidification can have direct consequences on the balance of ecosystems, acting on the basis of microbial components (Coelho et al., 2013), and causing a greater dispersion and availability of pollutants, intensifying their effects on the marine biota. Considering the current state, and that measures such as the local protection of species and areas are not fully effective to mitigate (Soto-Navarro et al., 2021) or reverse the trends of pollution, the implementation of containment/prevention measures for all kinds of pollutants, mainly through regulatory instruments and by vast plans of decontamination, are urgently required.

\subsection{Direct physical habitat disruption and artificialisation}

In the past decades, the European date mussel (Lithophaga lithophaga) fishery has been the main anthropogenic source of direct physical damage on shallow rocky reefs (e.g., Fanelli et al., 1994; Bevilacqua et al., 2006). This destructive fishing practice, which requires breaking rocky surfaces and removing the whole benthic assemblage to collect the endolithic bivalves, has led to the destruction of large extensions of rocky reefs in the whole basin, from Morocco to Israel (Colletti et 
al., 2020). Though banned since the end of 1980s in most Mediterranean countries, the date mussel fishery still continues illegally in several regions (Katsanevakis et al., 2011; Colletti et al., 2020) and the current extent of damaged areas remains largely unknown. Other activities associated with human visitation, such as trampling, anchoring, and diving can cause direct damage to shallow benthic communities inhabiting rocky reefs (Milazzo et al., 2004; Guarnieri et al., 2012), although these impacts are often limited and locally concentrated in crowded sites.

For hard substrates at greater depths, and especially for coralligenous outcrops and maërl, bottom trawling is primarily responsible for habitat degradation and loss. Trawling may have either a direct physical impact caused by otter boards and nets that destroy the three-dimensional structure of arborescent corals colonies or an indirect impact due to sediment resuspension and deposition on benthic habitats (Savini et al., 2014; D’Onghia et al., 2017). Altered sedimentary regime due to bottom trawling for crustaceans (i.e., Aristeidae shrimps, Norway lobster) is one of the main threats for fragile cold-water corals (Latras et al., 2016). In the Mediterranean Sea, fishing efforts by trawling are intensifying especially at depth <200 m (Ferrà et al., 2018), suggesting a future increase in the extent and magnitude of deterioration and loss of rocky habitats in the circalittoral zone.

Coastal habitats in the Mediterranean Sea are experiencing profound modifications also due to the continuous expansion of coastal anthropization since the 1950s (Airoldi and Beck, 2007; Bugnot et al. 2020). From 1990 until 2000, the surface of coastal artificial structures within $1 \mathrm{~km}$ from the shoreline increased on average by $\sim 3 \%$, whereas coastal armouring interested $\sim 8 \%$ of coasts (EEA, 2006). Recent estimates projected an increase in urbanized areas below $20 \mathrm{~m}$ of elevation ranging between 67\%-104\% in many Mediterranean countries (Wolff et al., 2020). Coastal development may involve the introduction of artificial substrates but also massive land reclamation, which causes the irreversible destruction/loss of original habitats. Recent data concerning the Monaco Principality (see http://www.medam.org), for instance, show that $>90 \%$ of the coastline and $>90 \%$ 
of shallow marine habitats (between 0 and $10 \mathrm{~m}$ depth, including rocky reefs) have been destroyed/artificialized, with extensive land reclamation allowing the small country to gain more and more "emerged surfaces" to build. These massive interventions of coastal engineering may appear punctual and irrelevant at the Mediterranean scale, but they deeply and irreversibly impact local marine biodiversity with the potential risk of scaling-up effects at regional or even larger scale with future expansion of these practices.

Besides the direct effects, indirect effects on rocky reef communities due to the introduction of artificial substrates, coastal urbanization, coastline modifications and ensuing alterations of sedimentary regimes are even more harmful (Bulleri, 2005; Airoldi et al., 2015). The presence of breakwaters, sea walls, jetties, and other man-made structures in coastal environments, as well as offshore oil and gas platforms could affect species populations and communities from native hard substrates by modifying natural patterns of ecological connectivity, either enhancing or dampening dispersal and trophic connections (Bishop et al., 2017). Assemblages on artificial structures are generally less diverse and complex than those on natural hard substrates, which make them more prone to be colonized by non-indigenous species (NIS) and to act as stepping stones disproportionately favouring the spread of alien species over native rocky reef species (Airoldi et al., 2015). Moreover, coastal engineering often relates to sediment resuspension and dislodgement as a direct consequence of interventions (e.g., dredging) or indirectly by modifying hydrodynamic coastal regimes, causing pulse or chronic increases in water turbidity and sedimentation. Burial, abrasion, and limitation of photosynthetic activity due to increased sediment suspension and deposition may drastically curb settlement, recruitment and survival abilities of sessile organisms, causing dramatic changes in rocky reef communities, which typically exhibit a shift from complex and highly diverse algal canopies towards homogenized assemblages dominated by a few sedimenttolerant turf-forming algae and suspension feeders (Airoldi, 2003; Ballesteros, 2006; Claudet and Fraschetti, 2010). 
Eco-engineering could be of help in mitigating potential impact of man-made marine structures and, in some cases, restoration actions could effectively sustain the recovery of damaged habitats. Reversing this trend should necessarily imply a radical rethinking of the use of marine space, especially in urban and periurban coastal areas (Airoldi et al., 2021), along with a consistent reduction of direct physical impacts.

\subsection{Overfishing}

Mediterranean rocky reefs along with their food webs are well known to be diverse, complex and, to some extent, fragile. Modern and traditional ecological knowledge can be paired with the long tradition of natural history studies in the Mediterranean to better understand temporal trajectories of changes attributable to human activities. Mediterranean rocky reefs, from this perspective, have been exploited by humans for millennia (Sala, 2004), with many species of vertebrates (e.g., fishes) and invertebrates (e.g., sea urchins, molluscs, crustaceans) that have been fished/harvested since ancient times for food and decorative uses.

Fishing, both professional and recreational, is widely considered one of the major causes of community-wide alterations of Mediterranean rocky reefs (Font and Lloret, 2014; Sini et al., 2019). Fishing methods can be multi-specific (e.g., fixed nets) or target one or few species (e.g., spearfishing), but the overall result is often the alteration of trophic relationships through the depletion of ecologically important species, and mostly high-level predators.

An emblematic example of the impact of fishing on large fish predators concerns the dusky grouper Epinephelus marginatus, a commercially important species and one of the largest predators on Mediterranean rocky reefs. Targeted by commercial and recreational fishing, its abundance and size dramatically decreased in recent decades. Large groupers were fished since prehistory and then in Greek and Roman times in very shallow stands, while nowadays abundant and large groupers can be observed just in fully protected zones of well enforced MPAs or deeper than 25-30 m in areas 
open to fishing (Guidetti and Micheli, 2011; Giakoumi et al., 2017). However, the paradigm of fishing impact producing community-wide consequences in the Mediterranean rocky reefs relates to sparid fishes, which thrive in these habitats and are targeted by professional and recreational fishers (Guidetti and Sala, 2007). Some sparids of high commercial value belonging to the genus Diplodus (especially the seabreams Diplodus sargus and D. vulgaris) actively feed on sea urchins. These seabreams have the potential of shaping the structure of entire communities associated with subtidal rocky reefs (Sala et al., 1998; Guidetti, 2006) as they might control the abundance of sea urchins and, indirectly, of erect macroalgae. Overfishing these seabreams may trigger a trophic cascade: whenever fishing reduces seabream abundance and size, sea urchin populations are released from predation and then dramatically increase, erect macroalgal forests disappear due to overgrazing and are replaced by the so-called barren grounds (Fig. 3). This transition implies a dramatic loss of biodiversity (of fish, invertebrate and algal species) and consequently of important ecosystem functions and services (e.g., reduced carbon sequestration, decreased vegetal biomass and detritus available for consumers, reduced three-dimensional habitat available for juvenile/adult fishes and invertebrates; Sala et al., 1998; Guidetti, 2006; Cheminée et al., 2013; Prato et al., 2013). Such species- to community-wide consequences of overfishing in subtidal rocky reefs can be effectively reversed with the creation of well enforced MPAs, especially if large enough to include species' home range (Guidetti et al., 2014, Di Franco et al., 2018).

Overfishing is not limited to infralittoral rocky reefs, but there is clear evidence of the impact of unregulated harvesting on mediolittoral limpets. In particular, the giant Mediterranean limpet Patella ferruginea, an endemic species harvested by man since prehistory (Fa, 2008), is the most endangered marine macroinvertebrate in the Mediterranean Sea. Presently, its distribution is restricted to only a few sites along the western Mediterranean rocky shores where, although officially protected (Annex IV of the Habitats Directive and Annex II of the Berne and Barcelona Conventions), limpet populations are declining at an alarming rate due to poaching in MPAs (Coppa et al., 2016). Circalittoral rocky communities in some areas of the Mediterranean have been 
since long impacted by the red coral Corallium rubrum harvesting, performed using the destructive trawling gear called St. Andrew Cross, nowadays banned and replaced by the employment of specialized divers and ROVs (Cattaneo-Vietti et al., 2016). Clear and widespread impacts from lost debris/gears ascribable to both professional and recreational deep-water fishing activities on rocky substrates are reported to affect deep-water habitats and sessile organisms (Bo et al., 2014).

Finally, a quite often neglected point is the virtual elimination of large consumer species (i.e., monk seal, loggerhead turtle, sharks). These ecologically extinct megafauna were crucially important in terms of trophic interactions, and their removal certainly had strong ecological consequences on rocky reef ecosystems in the Mediterranean Sea (Sala, 2004; Zogaris and De Maddalena, 2014).

\subsection{Bioinvasions}

Non-indigenous species (NIS) are introduced by human activities, accidentally or intentionally and through multiple vectors (Mack et al., 2000). In the last decades, the number of NIS in the Mediterranean Sea has continuously increased and the most recent studies have documented the presence of >1000 marine NIS, more than half of which are established and widespread, with almost 120 species being definitively invasive (Zenetos and Galanidi, 2020). Most NIS entered the Mediterranean Sea through the Suez Canal (namely Lessepsian species; Rilov and Galil, 2009; Katsanevakis et al., 2014; Galil et al., 2015). Other important pathways of marine NIS introduction in the Mediterranean include maritime transport (ballast waters, or hull fouling), aquaculture, and the aquarium trade (Zenetos et al., 2012).

Not all NIS, however, exert negative ecological effects as those caused by invasive species. In fact, only a fraction of NIS, thanks to combinations of favourable abiotic and biotic factors in the recipient ecosystem, become invasive alien species (IAS), and may severely affect its functioning (Butchart et al., 2010). IAS are, indeed, among the most pernicious outcomes of global change 
(Geraldi et al., 2020), so that their spread has been suggested as being a case of "biopollution" (Occhipinti Ambrogi, 2021).

Bioinvasions are not only associated with IAS but can also be the result of native species outbreaks that, due to contingent conditions, proliferate well above the carrying capacity of their system. In the Mediterranean Sea, examples of the former include outbreaks of the NIS algae Ostreopsis cf. ovata (Mangialajo et al., 2011), the medusa Rhopilema nomadica (Giallongo et al., 2021), the fish Pterois miles (Dimitriadis et al., 2020) and Siganus rivulatus (Renanel et al., 2018); examples of the latter include outbreaks of the dinoflagellate Noctiluca scintillans (Hallegraeff et al., 2021), the medusa Rhizostoma pulmo (Basso et al., 2019) and the fish Pomatomus saltatrix (VillegasHernandez et al., 2015).

Some invaders have large direct structural or consumptive impacts on the local communities, and sometimes both. One of the best examples is the invasion of the two Indopacific herbivorous rabbitfish in the previous century, that, by overgrazing, have depleted lush macroalgal stands in the eastern Mediterranean (Sala et al., 2011; Verges et al., 2014). This overgrazing most probably also contributed (in combination with sea warming) to the collapse of sea urchin populations on the southeastern Levant reefs through competition for food that reduced population viability (Yeruham et al., 2015). The recent rapid invasion of the lionfish (P. miles) (Dimitriadis et al., 2020), a voracious predator that has already caused extensive ecological impacts in the Caribbean Sea (Albins, 2015), is also expected to cause extensive ecological impacts on reefs in the region. IAS can also exert indirect, and often elusive, effects on biological and behavioural traits of native species. A good example of an invader with such a potential is the green alga Caulerpa cylindracea, native to southwestern Australia, reported for the first time in the Mediterranean Sea along the coasts of Tunisia in 1990 and then rapidly spreading in the whole basin (e.g., Piazzi et al., 2016; Rizzo et al., 2017). The basin-scale outbreak of this alga is likely due to its capacity to thrive in either hard or soft substrates at depths ranging from 0 to $>70 \mathrm{~m}$ (Klein and Verlaque, 2008) and to 
easily invade ecosystems already degraded by other anthropogenic stressors (Ceccherelli et al., 2014; Piazzi et al., 2016).

At the same time, $C$. cylindracea is among the most paradigmatic examples of chemical pollution mediated by molecules produced by the living biota. Caulerpenyne, caulerpine and caulerpicin, are the most abundant and investigated secondary metabolites of $C$. cylindracea, and all possess biological properties such as allelochemical, neurotoxic and cytotoxic activities (Raniello et al., 2007), which, by interfering native species, may contribute to the invasion potential of the alga. Despite the toxicity of these metabolites, $C$. cylindracea has become an important food item in the diet of the common Mediterranean seabream Diplodus sargus, whereas recent evidence indicates the presence of the alga in stomach contents of both other native Mediterranean fishes (i.e., the sparids Spondyliosoma cantharus, Sarpa salpa, Diplodus vulgaris, and the scarid, Sparisoma cretense) and the siganid Lessepsian migrant, Siganus luridus (Felline et al., 2017).

Such a 'new' diet has been related to the appearance of cellular and physiological alterations in fish, which include enhanced oxidative stress, the onset of genotoxic damage and the possible appearance of neurotoxic damage and anomalous behaviour that can lead to higher mortality rates (Felline et al., 2012). Fish consuming C. cylindracea show important changes in the gonadosomatic index (GSI) and a significant induction of the vitellogenin gene expression, altogether indicating the alteration of gross gonad morphology and possible adverse implications on the fish reproductive performance (Gorbi et al., 2014). Also, the ingestion of C. cylindracea causes a sort of behavioural relaxation in fish, which could hamper, especially in juveniles, their ability to escape predators.

The tropicalization of the Mediterranean by the interaction of rapid warming and the invasion of thermophilic species, and especially macroalgae (Israel and Einav, 2017), is already leading to the complete restructuring of the reef communities in the southeast Levantine basin (Rilov et al., 2019a), which evidently also transforms reef ecosystem functions (Peleg et al., 2020). Concern is also raising because either NIS and IAS could also favour the introduction and spread of new 
pathogens, potentially harmful to native species and, through cascading effects, on the entire ecosystem.

In contrast to the terrestrial realm, in marine ecosystems, where most of NIS have larval (and sometimes adult) dispersion stages that are practically impossible to counteract, and/or possess peculiar biological traits (like the ability to produce new propagules even from fragments; Bulleri et al., 2018a; Gribben et al., 2018), eradication is impossible, unless at a very early stage of introduction. Nevertheless, for some invasive species, control of their populations can be achieved through dedicated management measures, including commercial exploitation, which could mitigate the negative effects of IAS on native communities and ecosystems (Giakoumi et al., 2019; Rotter et al., 2020).

\subsection{Climate change}

Anthropogenic climate change is a major driver of global biodiversity change (Poloczanska et al., 2013), and projections of many ecosystems seem grim under business-as-usual or milder emission scenarios (Gattuso et al., 2015). Multiple climate-related pressures are emerging in ocean systems including warming, acidification, deoxygenation, increased storminess, sea level rise and changes in circulation. Consequently, many marine ecosystems are rapidly restructuring (or even collapsing, Burrows et al., 2019; Garrabou et al., in press) under the effects of climate change, which often interact with non-climatic stressors (Gissi et al., 2021).

The Mediterranean Sea is considered a hotspot for climate change (Cramer et al., 2018). Satellite sea surface observations indicate that the Mediterranean has warmed by $1.48^{\circ} \mathrm{C}$ on average for the entire basin over the 1982-2018 period (Pisano et al., 2020), with a rate 3-6 times faster than the warming rate of oceans globally (Cramer et al., 2018). The increase of mean temperature has been related to the increase of the frequency and intensity of extreme temperature conditions, i.e. marine heat waves (MHW; Darmaraki et al., 2019). However, the warming trend is uneven across 
Mediterranean marine ecoregions, showing higher warming in eastern ecoregions than in the Western ones (Skliris et al., 2012; Salat et al., 2019).

The increase in temperature particularly affects water masses from surface down to $80 \mathrm{~m}$ depth causing major impacts to the reef assemblages through two main processes: the shift in abundance and distribution of indigenous species and NIS and the occurrence of unprecedented mass mortality events (MMEs). Current warming is driving the decline in abundance of cold-water affinity species (Azzurro et al., 2019) in favour of warm-water affinity species. These changes are affecting different taxa, including keystone herbivores like sea urchins (Yeruham et al., 2015), and are rapidly reshaping the composition of reefs across the entire basin. Two main movement patterns can be recognized: (i) native warm-affinity species are moving northward, while the range of geographic distribution of cold-affinity species is progressively shrinking, and (ii) warm-adapted NIS that entered through the Suez Canal are moving westwards replacing and competing with native species. MMEs have been associated with intense MHWs, which have affected a wide range of rocky reefs from the infralittoral and circalittoral zones by causing severe impacts (with mortality rates up to $80-90 \%$ ) on at least 100 macrobenthic species (macroinvertebrates, macroalgal and seagrasses), encompassing 9 phyla (Garrabou et al., 2019). The most severe ones occurred in 1999 and 2003 when more than 30 macrobenthic species along thousands of kilometres of coastlines were affected (Garrabou et al., 2009). Besides these events, several other large scale MMEs as well minor episodes which are usually more restricted in geographic extent and/or number of affected species have been reported (Garrabou et al., 2019). Most evidence comes from the coldest areas of the Mediterranean (e.g., the northern Adriatic Sea), especially in shallow coralligenous reefs where gorgonians and sponges suffered extensive impacts (Garrabou et al., 2019).

Evidence of impacts related to other climate-related alterations, such as acidification, sea-level rise and deoxygenation, are currently lacking in the scientific literature. Ocean acidification is occurring in the Mediterranean Sea (Kapsenberg et al., 2017), but it does not seem to be at levels that may 
cause changes to rocky reefs and associated communities yet. However, in-situ surveys and experiments along natural $\mathrm{CO}_{2}$ gradients as well as laboratory experiments have shown that acidification may strongly affect reef communities by 2100 (Milazzo et al., 2014; Linares et al., 2015). Furthermore, sea level rise is expected to affect mediolittoral reefs through the reduction of the associated biodiversity and the alteration of metabolic rates of marine organisms (Rilov et al., 2021).

Climate change is already severely transforming Mediterranean reefs across all ecoregions. There is mounting evidence of multiple collapse of cold-affinity, habitat-forming and keystone reef species, which will be exacerbated by future reduction in $\mathrm{pH}$ of sea water and sea-level rise (Sala et al., 2011; Sarà et al., 2014; Rilov, 2016; Azzurro et al., 2019). The interaction of these processes will likely promote the shift of Mediterranean reef communities from temperate-Atlantic affinity towards Indopacific affinity through both regional extinctions of native species and the establishment of NIS (see also paragraph 3.4), first in the Levantine basin and in the future, further westward and northward, with profound changes in the functioning of reef ecosystems.

\subsection{Cumulative human pressures}

The Mediterranean Sea ecosystems are under high and escalating pressure from multiple uses and stressors (Lesjeune et al., 2010; Coll et al., 2012; Micheli et al., 2013), which have led to major shifts in marine ecosystems and widespread conflict among marine users (Airoldi and Beck, 2007; Abdulla et al., 2008; Ferretti et al., 2008; Claudet and Fraschetti, 2010). Because of such intense pressure, the Mediterranean is characterized as a sea 'under siege' (Coll et al., 2012).

The combination of multiple pressures from fishing, pollution, warming, acidification, direct habitat alteration and biological invasion makes the Mediterranean Sea one of the most impacted marine ecoregion globally (Halpern et al., 2008; Micheli et al., 2013). A recent global analysis showed that cumulative impacts to marine ecosystems are increasing in $60 \%$ of the ocean, including the 
Mediterranean Sea (Halpern et al., 2019). In the Mediterranean, the Levantine Sea, the Sicily Channel, parts of the Ionian, Alboran Sea and the western Mediterranean, particularly along the coastlines of Morocco and Algeria, have undergone significant increase in cumulative impacts over a period of only a decade (2003-2013), and no region has seen a decline in cumulative impact over this time period (Fig. 4A).

Mediterranean rocky habitats are subject to multiple pressures (Fig. 4B,C). Summarizing the evidence reported in the previous paragraphs, they are affected by overfishing, which reduces biomass and diversity, alters food web structure and interactions - in some cases triggering trophic cascades and shifts to low-diversity "barren" states (Sala et al., 1998; Micheli et al., 2005) - or directly impacts populations and alters habitat through removal of habitat forming species (e.g., red coral) and destructive practices, such as the seafloor and benthic assemblage removal associated with illegal date mussel harvesting (Guidetti, 2011). Increased sediment and nutrient loadings lead to benthic community shifts and eutrophication of the water column (Airoldi, 2003). Biological invasions, including by macroalgae and herbivorous rabbitfishes (Siganus spp.) have also resulted in invasive monocultures (e.g., of Caulerpa spp.) or desertification (Cebrian and Rodriguez-Prieto, 2012; Sala et al., 2011). Major, escalating threats to Mediterranean rocky reefs are temperature warming and MHWs, which are causing species range shifts, reef tropicalization, and mass mortalities (Garrabou et al., 2009).

Climate drivers are the main contributors to increased cumulative impact to rocky reefs, but overfishing and pollution are also key drivers of increased impact (Fig. 4B,C). Compared with other habitats, rocky reefs are impacted by the largest suite of different stressors, even though the magnitude of impact for some is lower than for several other ecosystem types (Fig. 4C). Expanding and strengthening rocky reef protection through the establishment and improved management of marine protected areas, and promoting climate resilience by reducing cumulative impact are key priorities for reversing these escalating trends of reef degradation. 


\section{Conservation achievements and next targets}

\subsection{Current conservation measures}

Rocky reef ecosystems are in peril at basin scale, with increasing evidence of ongoing regime shifts across habitats (Claudet and Fraschetti, 2010; Benedetti-Cecchi et al., 2019). Measuring progress to the European 2020 Biodiversity Strategy, Gubbay et al. (2016) documented that a critical proportion of rocky reef ecosystems are either vulnerable or endangered. They included macroalgaldominated communities and circalittoral rocks, mussel and oyster beds and biogenic concretions such as those of the red algae Lithophyllum byssoides, platforms formed by the algae Neogoniolithon brassica-florida and the gastropod Dendropoma petraeum in the European Red List of Habitats. However, the report highlighted that insufficient quantitative data often prevent determining the status of most marine ecosystems, suggesting that the list might be even longer than currently assumed to be.

There is a strong need for prioritizing conservation initiatives for these productive, diverse and vulnerable environments. Addressing the status of Mediterranean infralittoral rocky reefs, Bevilacqua et al. (2020) reported that two-thirds of sites included in their study were classified to be in moderate to poor conditions. While it should be recognized that $>50 \%$ of investigated sites for infralittoral reefs were within MPAs and/or the European Conservation Network (i.e., Natura 2000 sites), care should be given in not overestimating the potential benefits of those conservation strategies to preserve the integrity of rocky reef ecosystems (Fig. 5).

Applying the recently developed Regulation-Based Classification System for MPAs (Horta e Costa et al., 2016), Claudet et al. (2020) showed that while the 1062 MPAs in the Mediterranean Sea cover $6 \%$ of the Mediterranean Basin, $95 \%$ of the total protected area lacks regulations to reduce human impacts on biodiversity. Unevenly distributed across political boundaries and eco-regions, effective levels of protection for biodiversity conservation represent only $0.23 \%$ of the 
Mediterranean Basin (Zupan et al., 2018). In the French Mediterranean, while infralittoral rock and other hard substrata are the habitats most covered by full or high protection, only $2.6 \%$ of these habitats receive such levels of protection (Claudet et al., 2021). It is clearly evident that current efforts are insufficient at managing human uses of nature at sea and protection levels should be increased to deliver tangible benefits for biodiversity conservation in general and for these habitats in particular. There are few exceptions. A systematic review along the Italian coasts about the occurrence and conservation status of Cystoseira s.l. concluded that while only a negligible proportion of their populations was protected (3\%) before 2000 , the proportion of "protected" populations has increased in recent years to $77.8 \%$, with nearly two thirds of the populations included in MPAs (Tamburello et al., unpublished data). MPAs might guarantee protection to Cystoseira s.1., with recent evidences showing higher coverage inside MPAs compared to unprotected areas (Di Franco et al., 2021), by limiting coastal urbanization and overfishing, including illegal and destructive practices (Colletti et al., 2020), and avoiding overgrazing allowing the recovery of high-level predators, controlling herbivores populations, or directly limiting the discard of dismissed fishing gears.

Despite the European Union having progressed in implementing an imponent legal framework for marine resources protection and management, there are still important gaps (Fraschetti et al., 2018) and intertidal and subtidal rocky reef ecosystems suffer from the lack of specific conservation interventions. Currently, there are no specific conservation actions for macroalgal habitats and the action plans on Protecting Coralligenous and other calcareous BioConcretions in the Mediterranean developed by Mediterranean institutions are not legally binding. The consequence is that, for most of the Mediterranean Sea, the status of the category Reef (1170) of the Habitat Directive is insufficient in terms of both 'structure and functioning' and 'future prospects'.

\subsection{Future conservation needs}


The failure of past conservation measures to achieve large-scale outcomes for Mediterranean reefs stresses the urgent need for holistic, integrated, effective and more ambitious conservation strategies to improve their status (Fig. 6). Shifting from the existing paper-park-dominated networks of MPAs (Claudet et al., 2020) to well-connected networks with extended no-take areas and wellmanaged multi-use MPAs that can effectively contribute to the recovery of reef ecosystems is crucial (Bevilacqua et al., 2006; Sala et al., 2012; Thibaut et al., 2017). The ambitious new European Biodiversity Strategy for 2030 and its targets for $30 \%$ protection - 10\% strict protection offer an unprecedented opportunity to achieve large scale conservation of rocky reefs, substantially upgrading the current low level of the Mediterranean being effectively protected. Towards these targets, it is critical to apply a systematic conservation planning process (Katsanevakis et al., 2020), through which the full compositional and functional variability and diversity of rocky reef ecosystems is adequately represented (Bevilacqua and Terlizzi, 2020).

More than that, reduction of stressors also outside MPAs is critical. Better fisheries management and a strong overall reduction of fishing effort also in non-protected areas are needed to improve the status of rocky reef ecosystems at a large scale. A reduced fishing pressure has been related to substantially increased fish abundance and biomass in non-protected areas, including that of predators (Sini et al., 2019), which in many cases can be essential for the recovery of reef ecosystems via cascading effects (Sala et al., 1998; Hereu, 2006). Better integration of conservation strategies and the ecosystem approach of fisheries management in the EU Common Fisheries Policy and the regional fisheries management by the General Fisheries Commission for the Mediterranean will be beneficial for both reef conservation and the related Mediterranean fisheries, which are currently largely unsustainable (Colloca et al., 2017).

The need to include biological invasions and climate change considerations in conservation strategies has been highlighted as a necessity but also a grand challenge (Micheli et al., 2012; Katsanevakis et al., 2020). Despite the effectiveness of protection measures within MPAs, invasive 
species and climate change can substantially compromise any efforts to conserve or restore reef ecosystems (Rilov et al., 2018; Dimitriadis et al., 2021), often enhancing the impacts of overfishing, pollution and other stressors (Gissi et al., 2021). Although there are important progresses in incorporating climate change in conservation strategies (Johnson and Kenchington, 2019; Katsanevakis et al., 2020), developing frameworks to incorporate biological invasions in conservation planning (Mačić et al., 2018), and prioritizing management measures for invasive species (Giakoumi et al., 2019), current guidelines and practices for expanding the network of MPAs in the Mediterranean totally ignore the issues. Future conservation strategies (Fig. 6) need to be adaptive to account for change, identify and consider climate refugia for reef conservation and restoration, set different targets for climate change hotspots focusing on securing reef ecosystem functioning, account for both negative and positive impacts of alien species and adopt appropriate mitigation measures, and promote the identification of climate-driven eco-evolutionary changes and climate-resistant algal populations to be used for reef restoration (Rilov et al., 2019a; 2020b; Katsanevakis et al., 2020).

\subsection{Frontiers in the restoration of rocky habitats}

The exacerbated speeds of global and local changes from multiple stressors are decreasing the resilience of rocky habitats globally (Airoldi et al., 2009), hampering their ability to recover naturally following passive management efforts (O'Leary et al., 2017). With the pace of current loss and degradation there is a need for more active intervention-based approaches that can integrate social, economic and environmental objectives (Abelson et al., 2016). Marine habitat restoration is an emerging field to actively reverse the degradation and loss of natural ecosystems (Abelson et al., 2020) recognized by the UN Decade on Ecosystem Restoration (2021-2030). Here, we use restoration in its broadest possible meaning (Airoldi et al., 2021), encompassing multiple approaches to both actively repair the damaged marine life as well as to "green" the currently grey 
hard infrastructure. Examples include active interventions to restore canopy forming seaweeds in both their natural habitats (De La Fuente et al., 2019b) as well as in artificial habitats used as "gardens" where their natural habitat is under threat (Perkol-Finkel et al., 2012).

Marine restoration practice and governance are still in their infancy both in terms of research as well as political, legal and economic support (Abelson et al., 2020; Bayraktarov et al., 2016). The challenge of safeguarding ecosystem services is especially prominent for the Mediterranean Sea, where knowledge of marine ecosystems status and dynamics is still fragmented (Airoldi and Beck, 2007; Gianni et al., 2013). Yet, significant research is emerging, aiming at identifying both the feasibility and self-sustainability of restoration efforts as well as adequate techniques and spatial layouts (Claudet and Fraschetti, 2010). Concerning rocky habitats, most of these research efforts have focused on the recovery of macroalgal stands (Verdura et al., 2018; Guarnieri et al., 2020; Orlando-Bonaca et al., 2021; Savonitto et al., 2021). Recent efforts have also focused on the restoration of populations of invertebrate species, such as the scleractinian coral Astroides calycularis (Musco et al., 2017), the bryozoan Pentapora fascialis (Pagès-Escolà et al., 2020), and the limpet Patella ferruginea (Ferranti et al., 2021), with many novel technologies and approaches emerging, such as or the use of electro-mineral accretion for enhancing the settlement of the red coral Corallium rubrum (Benedetti et al., 2011). Increasing research has also focused on the bioenhancement of artificial habitats by increasing surface topographic complexity, or by using more environmentally friendly construction materials, with some successful examples but also uncertainties about the consistency of the benefits (Strain et al., 2021).

There is real interest and critical opportunities to support marine restoration actions in the Mediterranean sea for the benefit of people and nature. Large-scale, long-lasting test projects are needed to nurture the most innovative ideas, overcome the barriers to scaling and address some technical challenges. This restoration, however, will rarely, if ever, result in a return to a historical state, forcing us to actively consider what we think those ecosystems should consist of. 


\section{Next challenges and perspectives in ecological research}

Understanding how rocky reef communities persist in the face of intensifying climate change and escalating cumulative anthropogenic disturbances is a research priority to preserve the structure and functioning of these systems and to promote informed conservation policies. Persistence is generally understood in terms of components of stability, such as resistance and resilience to perturbations and adaptation (Donhue et al., 2016; Hillebrand et al., 2018). Despite increasing research efforts to elucidate the effects of natural and anthropogenic disturbances on rocky reef communities, a clear understanding of the mechanisms underpinning stability and adaptation has remained elusive.

Regime shifts in macroalgal forests are a case in point. Several studies have documented the collapse of these systems in response to pollution, urban development and degrading environmental quality more generally (Benedetti-Cecchi et al., 2001; Wernberg et al., 2011; Strain et al., 2014). Experiments and models have shown how these responses may involve nonlinearities and thresholds, implying abrupt transitions (regime shifts) towards alternative states, often characterized by algal turfs or barren habitats (Benedetti-Cecchi et al., 2015; Rindi et al., 2017) (see Fig. 3). The occurrence of nonlinear dynamics implies the existence of reinforcing (feedback) mechanisms that stabilize the system in one state or the other (Scheffer, 2009). For example, successful recruitment is more likely to occur nearby dense stands of canopy species with limited dispersal capabilities (e.g., Capdevila et al., 2018). Hence, an expanding patch of algal canopy can reinforce itself because it will produce larger and larger numbers of propagules as it grows. Similarly, an expanding patch of canopy algae can become increasingly resistant to dislodgement owing to the coalescence of an increasing number of holdfasts, as observed in some canopy-forming algae (Gonzáles et al., 2015). Reinforcing mechanisms should also be at work to stabilize the alternative states. In principle, established mats of algal turfs may persist by inhibiting the recruitment of 
canopy algae (Benedetti-Cecchi and Cinelli, 1992) and by reducing desiccation stress through water retention in intertidal habitats. Both mechanisms are expected to strengthen as algal turfs grow and develop into thick mats.

These runway mechanisms have been invoked to explain the nonlinear dynamics observed in Ericaria amentacea var. stricta (Benedetti-Cecchi et al., 2015; Rindi et al., 2017). However, the limited dispersal of zygotes in this species has been inferred mostly from laboratory studies and the extent to which coalescence of holdfasts increases stability remains unquantified (Clayton, 1992). Similarly, the stabilizing mechanisms proposed for algal turfs have been rarely tested. All these reinforcing feedbacks involve density-dependent processes as a common underlying cause. Densitydependent processes are pervasive in ecological communities and similar feedbacks may occur generally across species and habitats (Aubier, 2020). For example, mechanisms similar to those described for algal canopies may stabilize benthic communities dominated by suspension feeders, such as gorgonian forests. To the best of our knowledge, no single study has investigated these mechanisms on rocky shores and linked them to stability. We believe the lack of empirical testing of essential stabilizing mechanisms is a critical knowledge gap that hampers our ability to anticipate the response of rocky reef communities to environmental change.

Understanding the mechanisms underpinning variation in species tolerance to changing climates will be key to preserving the biodiversity and functioning of coastal rocky systems through informed restoration and conservation (e.g., MPA networks, genetic rescue) practices. This will require the coupling of common garden and reciprocal transplant experiments with cutting-edge genomic and transcriptomic techniques (Johnson et al., 2021). In common garden experiments, the exposure of offspring and adults from different populations to a common set of environmental conditions, including extreme events, such as heatwaves, would allow assessing variation in their performance and fitness across populations. Aquatic mesocosms appear as the elective playground for this kind of experiments. While the advantages of a fine control of environmental conditions in 
artificial settings are undisputable, field experiments offer the opportunity to assess species response to changing conditions while embedded into the complex web of species interactions. In particular, reciprocal transplant experiments in the field would represent a powerful tool to identify genetic versus phenotypic plasticity adaptation of populations in natural settings. These experiments will be particularly valuable when studied populations span broad environmental gradients (Johnson et al., 2021). This implies taking into account variations in key environmental and climatic variables over a hierarchy of spatial scales, from geographic to local. The relevance of assessing variations in a species tolerance to warming conditions among populations at edges of its latitudinal distribution is widely acknowledged (Hampe and Petit, 2005; Bulleri et al., 2018b). However, latitudinal gradients are not always linearly correlated with seawater and air temperature and, even less, with the degree of mean change or the intensity and frequency of extreme events (Helmuth et al., 2002; Burrows et al., 2011). For example, viable populations from areas that have been, historically, exposed to extreme events of larger intensity and/or more frequently can be expected to exhibit a greater tolerance to adverse climatic conditions (Coleman and Wernberg, 2020). Thus, maps of past climatic conditions may be of aid in selecting relevant populations for tolerance/adaptation studies.

Dispersal potential of target species represents another key aspect to take into account while attempting to assess variations in local adaptation since connectivity among populations is paramount for sustaining climate-readiness of restoration activities and MPA networks. Assessing local adaptation across fine-scale gradients in environmental conditions appears as crucial in shortdispersal species. In the Mediterranean, canopy-forming macroalgae are often distributed from the surface to depths below the seasonal thermocline and individuals only a few $\mathrm{m}$ apart are, thus, exposed to very different thermal environments. Likewise, substrate topography, orientation and slope can create a fine-scale thermal mosaic in intertidal environments. Reciprocal transplants of individuals, possibly both adults and offspring, from different depths, heights on the shore or from 
intertidal microhabitats characterized by benign versus adverse environmental conditions (i.e., desiccation, temperature) would provide an insight into local adaptation within populations and, hence, into their potential to persist in the face of change.

Genomic tools can complement the information generated by field and mesocosm experiments providing a mechanistic understanding of the genetic basis of local adaptation. Progressive reduction of costs of next-generation sequencing techniques has fostered the production of genomic information and is giving momentum to conservation genomics of marine forests (Mamo et al., 2021). For instance, Wood et al. (2021) characterized neutral and adaptive genetic diversity in the brown seaweed Phyllospora comosa and how it correlates with temperature, generating an insight into genetic vulnerability under warming climates, crucial information for climate-proof restoration of this species. In addition, improvement of transcriptomic analyses can allow assessing how relevant environmental variables influence gene expression, fostering a mechanistic understanding of species physiological response to changing climates (Li et al., 2019).

A research agenda on ecological persistence and adaptation should develop following state-of-theart approaches and methodologies. For example, distributed experiments might be used to assess the generality (or lack thereof) of dispersal limitation and density-dependent processes along geographic gradients and in contrasting environmental conditions. The Mediterranean provides an invaluable model system for this purpose. New technological tools such as environmental DNA should be calibrated and used to capture phenological events, such as massive reproductive outputs of algae and invertebrates. Novel approaches that combine observational and experimental data in the same analytical framework have been proposed to increase the scale and inferential strength of ecological studies (Benedetti-Cecchi et al., 2018). The implementation of these approaches is facilitated by the increasing availability of open datasets and by joint collaborative efforts among researchers. Our final recommendation is that a research agenda on persistence and adaptation 
should focus primarily on habitat-forming species, since these contribute most to the structure and functioning of rocky reef communities.

\section{The fate of Mediterranean rocky reefs}

The fate of Mediterranean rocky reefs remains highly uncertain, as is the fate of the entire basin, but current trends in cumulative human pressure and climate change do not bode well for a bright future. Next years will be decisive for the persistence of Mediterranean rocky reef ecosystems as we have known them so far. Most probably, we will see a relatively fast process of oversimplification of their communities, both in terms of structure and functioning, accompanied with a depletion of biodiversity and an increased biotic homogenization driven by opportunistic native species and NIS. Bioconstructions in the midlittoral zone, such as vermetid reefs, which already have limited extension in the basin and are highly fragile and fragmented, will drastically reduce or disappear being more exposed to climate-related disturbances. Infralittoral algal forests will continue to shrink, being replaced by less structured communities dominated by smaller erect algae, algal turfs and crusts. Deeper communities in the circalittoral zone will be less affected by climate change, at least in the short-medium term. However, acidification and other interacting human stressors, sooner or later, will start to mine the growth rates of coralligenous outcrops enhancing bioerosive processes (Ponti et al., 2018). MHWs and MMEs, increased sedimentation and deoxygenation will contribute to simplify coralligenous communities, making them more similar to fouling assemblages. The loss of long-living ecosystem engineers, like gorgonians and large sponges, will trigger a gradual, and probably irreversible, process of habitat degradation, increasing the opportunity for NIS to spread and leading to less complex assemblages.

Changes will not be uniform over the entire Mediterranean Sea, but slower and smaller in areas less compromised by human impacts and less affected by climate-driven alterations. Rocky reefs in the eastern basin will become more and more tropicalized, losing their Mediterranean identity, whereas 
this progression will be delayed in the other regions, although early signals of change might also occur in previous cold-temperate areas (e.g., the northern Adriatic Sea). However, in the western Mediterranean Sea, the higher rates of intensification of fishing effort, spread of new pollutants, and of artificialization of rocky coasts will further undermine the resilience potential of reef ecosystems, making them more exposed to bioinvasions and more prone to collapse in the face of future climatic anomalies. In both regions, the process of reorganization (sensu Holling, 2001) of rocky reef ecosystems will probably be slower than current and future rates of disruption, altering, if not dismissing, the provision of essential goods and services for a long period. This will pose serious concerns (and, indeed, they are already raising) on the ability of socioeconomic systems of Mediterranean coastal areas, which largely rely on rocky reef integrity especially for tourism and small scale fisheries (UfMS, 2017), to adapt to these ecological changes.

The substantial expansion of the coverage and improvement of effectiveness of Mediterranean MPAs through the implementation of the European Biodiversity Strategy and the Green Deal, and the development of efficient conservation strategies, which beyond the structure may also allow preserving the functional diversity of reef communities (Bevilacqua and Terlizzi, 2020), are expected to contribute in decelerating or even reversing the declining trend of the ecological status of rocky reef ecosystems. Nevertheless, a number of challenges may compromise the effectiveness of future conservation strategies, and MPAs alone cannot be a panacea (Lubchenco et al., 2003). Climate change and biological invasions can keep increasing stress to reef ecosystems, and forthcoming socioeconomic pathways can lead to a wide range of plausible futures, with a varying effect in shaping priorities in marine policies and conservation (van Vuuren et al., 2014; RouraPascual et al., 2021). Progresses in ecological restoration will certainly be of help in contrasting the degradation of rocky reefs in the next years, although the intrinsic difficulties of restoration techniques and constraints to their application over large areas (Falace et al., 2018; Guarnieri et al., 2020) will probably relegate restoration to an ancillary role in their conservation or recovery. Moreover, hysteretic behaviour of reef ecosystems could vanish the attempts to restore their 
integrity in the absence of management strategies aiming at enhancing the wider environmental context (Anthony et al., 2015).

In 2012, the European Commission launched the Blue Growth Strategy (COM/2021/0494), identifying the European seas and oceans as the frontier for future sustainable socioeconomic development. The working concept of sustainable blue growth defines it as an economy that '...promotes economic growth, social inclusion and improved livelihoods while ensuring the environmental sustainability of the natural capital of the oceans and seas' (CINEA, 2021). This is not an easy task that requires balancing often conflicting needs within marine socioecological systems, implementing development strategies carefully tuned to match local contexts, and monitoring their effectiveness through specific indicators to ensure timely adaptations to environmental changes (CINEA, 2021). Given the current status, the pace of ongoing degradation of Mediterranean rocky reefs and future projections, any further use of their resources seems to be unrealistic. Therefore, at least for these coastal systems, the importance of the two elements composing the concept of blue growth should be reversed, emphasizing the need for a healthy status of reefs over the rush for new economic opportunities. Major efforts in policies and regulations specifically tailored for Mediterranean rocky reefs are urgently required to make the integrity of these habitats a priority for conservation and management at European and basin scale, and try to give the chance for a less troubled future to Mediterranean coastal ecosystems. 


\section{References}

Abdulla, A., Gomei, M., Hyrenbach, D., Notarbartolo di Sciara, G., Agardy, T., 2008. Challenges facing a network of representative marine protected areas in the Mediterranean: prioritizing the protection of underrepresented habitats. ICES J. Mar. Sci., 66, 22-28.

Abelson, A., Halpern, B.S., Reed, D.C., Orth, R.J., Kendrick, G.A., Beck, M.W., et al., 2016. Upgrading marine ecosystem restoration using ecological-social concepts. Bioscience, 66, $156-163$.

Abelson, A., Reed, D.C., Edgar, G.J., Smith, C.S., Kendrick, G.A., Orth, R.J., et al., 2020. Challenges for restoration of coastal marine ecosystems in the Anthropocene. Front. Mar. Sci., 7, 1-14.

Agnesi, S., Annunziatellis, A., Chaniotis, P., Mo, G., Korpinen, S., Snoj, L., et al., 2020. Spatial Analysis of Marine Protected Area Networks in Europe's Seas III. ETC/ICM Technical Report 3/2020, European Topic Centre on Inland, Coastal and Marine waters, 40 pp.

Airoldi, L., 2003. The effects of sedimentation on rocky coast assemblages. Oceanogr. Mar. Biol. Annu. Rev., 41, 161-236.

Airoldi, L., Beck, M.W, 2007. Loss, status and trends for coastal marine habitats of Europe. Oceanogr. Mar. Biol. Annu. Rev., 45, 345-405.

Airoldi, L., Beck, M.W., Firth, L.B., Bugnot, A.B., Steinberg, P.D., Dafforn, K.A., 2021. Emerging solutions to return nature to the urban. Oceanogr. Annu. Rev. Mar. Sci., 13, 445-477.

Airoldi, L., Connell, S., Beck, M.W., 2009. The loss of natural habitats and the addition of artificial substrata. In: Whal, M. (Ed.), Bottom Communities: Patterns, Dynamics, Diversity and Change Ecological Studies - Analysis and Synthesis, Springer Verlag, 269-280.

Airoldi, L., Turon, X., Perkol-Finkel, S., Rius, M., 2015. Corridors for aliens but not for natives: effects of marine urban sprawl at a regional scale. Divers. Distrib., 21, 755-768.

Albins, M.A., 2015. Invasive Pacific lionfish Pterois volitans reduce abundance and species richness of native Bahamian coral-reef fishes. Mar. Ecol. Progr. Ser., 522, 231-243. 
Albouy, C., Ben Rais Lasram, F., Velez, L., Guilhaumon, F., Meynard, C., Boyer, S., et al., 2015. FishMed: traits, phylogeny, current and projected species distribution of Mediterranean fishes, and environmental data. Ecology, 96, 2312-2313.

Almeida, Â., Solé, M., Soares, A.M.V.M., Freitas, R., 2020. Anti-inflammatory drugs in the marine environment: Bioconcentration, metabolism and sub-lethal effects in marine bivalves. Environ. Pollut. A, 263, 114442.

Anthony, R.N., Marshall, P., Abdulla, A., Beeden, R., Bergh, C., Black, R., et al., 2015. Operationalizing resilience for adaptive coral reef management under global environmental change. Glob. Change Ecol., 21, 48-61.

Aubier, T.G., 2020. Positive density dependence acting on mortality can help maintain species-rich communities. eLife, 10.7554/eLife.57788.

Azzurro, E., Matiddi, M., Fanelli, E., Guidetti, P., La Mesa, G., Scarpato, A., et al., 2010. Sewage pollution impact on Mediterranean rocky-reef fish assemblages. Mar. Environ. Res., 69, $390-397$.

Azzurro, E., Sbragaglia, V., Cerri, J., Bariche, M., Bolognini, L., Ben Souissi, J., et al., 2019. Climate change, biological invasions, and the shifting distribution of Mediterranean fishes: a large-scale survey based on local ecological knowledge. Glob. Change Biol., 25, 27792792.

Badreddine, A., Milazzo, M., Saab, M.A-A., Bitar, G., Mangialajo, L., 2019. Threatened biogenic formations of the Mediterranean: Current status and assessment of the vermetid reefs along the Lebanese coastline (Levant basin). Ocean Coast. Manage., 169, 137-146.

Ballesteros, E., 1989. Production of seaweeds in Northwestern Mediterranean marine communities: its relation with environmental factors. Sci. Mar., 53, 357-364.

Ballesteros, E., 1991. Structure and dynamics of Northwestern Mediterranean marine communities: a conceptual model. In: Ros, J.D., Prat, N. (Eds), Homage to Ramon Margalef or Why there is such a pleasure in studying Nature, Publicacions Universitat de Barcelona, 223-242. 
Ballesteros, E., 2006. Mediterranean coralligenous assemblages: a synthesis of present knowledge. Oceanogr. Mar. Biol. Annu. Rev., 44, 123-195.

Basso, L., Rizzo, L., Marzano, M., Intranuovo, M., Fosso, B., Pesole, G., et al., 2019. Jellyfish summer outbreaks as bacterial vectors and potential hazards for marine animals and humans health? The case of Rhizostoma pulmo (Scyphozoa, Cnidaria). Sci. Tot. Env., 692, 305-318.

Bavestrello, G., Bianchi, C.N., Calcinai, B., Cattaneo-Vietti, R., Cerrano, C., Morri, C., et al., 2000. Bio-mineralogy as a structuring factor for marine epibenthic communities. Mar. Ecol. Progr. Ser., 193, 241-249

Bayraktarov, E., Saunders M.I., Abdullah, S., Mills, M., Beher, J., Possingham, H.P., et al., 2016. The cost and feasibility of marine coastal restoration. Ecol. Appl., 26, 1055-1074.

Ben Rais Lasram, F., Guilhaumon, F., Albouy, , Somot, S., Thuiller, W., Mouillot, D., 2010. The Mediterranean Sea as a 'cul-de-sac' for endemic fishes facing climate change. Glob. Change Biol., 16, 3233-3245.

Benedetti-Cecchi, L., Airoldi, L., Bulleri, F., Fraschetti, S., Terlizzi, A., 2019. Chapter 8. Species Interactions and Regime Shifts in Intertidal and Subtidal Rocky Reefs of the Mediterranean Sea. In: Hawkins, S.J., Bohn, K., Firth, L.B., Williams, G.A. (Eds), Interaction in the Marine Benthos: Global Patterns and Processes, Cambridge University Press, 190-213.

Benedetti-Cecchi, L., Bulleri, F., Dal Bello, M., Maggi, E., Ravaglioli, C., Rindi, L., 2018. Hybrid datasets: integrating observations with experiments in the era of macroecology and big data. Ecology, 99, 2654-2666.

Benedetti-Cecchi, L., Cinelli, F., 1992. Effects of canopy cover, herbivores and substratum type on patterns of Cystoseira spp. settlement and recruitment in littoral rock pools. Mar. Ecol. Progr. Ser., 90, 183-191.

Benedetti-Cecchi, L., Pannacciulli, F., Bulleri, F., Moschella, P.S., Airoldi, L., Relini, G., et al., 2001. Predicting the consequences of anthropogenic disturbance: large-scale effects of loss of canopy algae on rocky shores. Mar. Ecol. Progr. Ser., 214, 137-150. 
Benedetti-Cecchi, L., Tamburello, L., Maggi, E., Bulleri, F., 2015. Experimental perturbations modify the performance of early warning indicators of regime shift. Curr. Biol., 25, 18671872.

Benedetti, A., Bramanti, L., Tsounis, G., Faimali, M., Pavanello, G., Rossi, S., et al. 2011. Applying cathodically polarised substrata to the restoration of a high value coral. Biofouling, 27, 799-809.

Bevilacqua, S., Guarnieri, G., Farella, G., Terlizzi, A., Fraschetti, F., 2018. A regional assessment of cumulative impact mapping on Mediterranean coralligenous outcrops. Sci. Rep., 8, 1757.

Bevilacqua, S., Katsanevakis, S., Micheli, F., Sala, E., Rilov, G., Sarà, G., et al., 2020. The status of coastal benthic ecosystems in the Mediterranean Sea: evidence from ecological indicators. Front. Mar. Sci., 7, 475.

Bevilacqua, S., Savonitto, G., Lipizer, M., Mancuso, P., Ciriaco, S., Srijemsi, M., et al., 2019. Climatic anomalies may create a long-lasting ecological phase shift by altering the reproduction of a foundation species. Ecology, 100, e02838.

Bevilacqua, S., Terlizzi, A., Fraschetti, S., Russo, G.F., Boero, F., 2006. Mitigating human disturbance: can protection influence trajectories of recovery in benthic assemblages? J. Anim. Ecol., 75, 908-920.

Bevilacqua, S., Terlizzi, A., 2020. Nestedness and turnover unveil inverse spatial patterns of compositional and functional $\beta$-diversity at varying depth in marine benthos. Divers. Distrib., 26, 743-757.

Bianchelli, S., Danovaro, R., 2020. Impairment of microbial and meiofaunal ecosystem functions linked to algal forest loss. Sci. Rep., 10, 19970.

Bishop, M.J., Mayer-Pinto, M., Airoldi, L., Firth, L.B., Morris, R.L., Loke, L.H.L., et al., 2017. Effects of ocean sprawl on ecological connectivity: impacts and solutions. J. Exp. Mar. Biol. Ecol., 492, 7-30. 
Bo, M., Bava, S., Canese, S., Angiolillo, M., Cattaneo-Vietti, R., Bavestrello, G., 2014. Fishing impact on deep Mediterranean rocky habitats as revealed by ROV investigation. Biol. Conserv., 171, 167-176.

Boero, F., De Leo, F., Fraschetti, S., Ingrosso, G., 2019. The Cells of Ecosystem Functioning: towards a holistic vision of marine space. Adv. Mar. Biol., 82, 129-153.

Branch, M., Thompson, R.C., Crowe, T.P., Castilla, J.C., Langmead, O., Hawkins, S.J., 2008. Rocky intertidal shores: prognosis for the future. In: Polunin, N.V.C. (Ed.), Aquatic Ecosystems - Trends and Global Prospects, Cambridge University Press, 209-225.

Bennett, N., Cisneros-Montemayor, A.M., Blythe, J., Silver, J.J., Singh, G., Andrews, N., et al., 2019. Toward a sustainable and equitable blue economy. Nat. Sustain., 2, 991-993.

Briton, F., Cortese, D., Duhaut, T., Guizien, K., 2018. High-resolution modelling of ocean circulation can reveal retention spots important for biodiversity conservation. Aquat. Conserv. Mar. Freshw. Ecosyst., 28, 882-893.

Bugnot, A.B., Mayer-Pinto, M., Airoldi, L., Heery, E.C., Johnston, E.L., Critchley, L.P., et al., 2020. Current and projected global extent of marine built structures. Nat. Sustain., 4, 33-41.

Bulleri, F., 2005. The introduction of artificial structures on marine soft- and hard-bottoms: Ecological implications of epibiota. Environ. Conserv., 32, 101-102.

Bulleri, F., Eriksson, B.K., Queirós, A., Airoldi, L., Arenas, F., Arvanitidis, C., et al., 2018b. Harnessing positive species interactions as a tool against climate-driven loss of coastal biodiversity. PLoS Biol., 16, e2006852.

Bulleri, F., Tamburello, L., Pusceddu, A., Bonechi, L., Cau, A., Moccia, D., et al., 2018a. Fragment quality and sediment organic loading regulate the survival of an invasive, clonal seaweed. Biol. Invasions, 20, 1953-1959.

Buonocore, E., Appolloni, L., Russo, G.F., Franzese, P., 2020. Assessing natural capital value in marine ecosystems through an environmental accounting model: A case study in Southern Italy. Ecol. Model., 419, 108958. 
Burrows, M.T., Bates, A.E., Costello, M.J., Edwards, M., Edgar, G.J., Fox, C.J., et al., 2019. Ocean community warming responses explained by thermal affinities and temperature gradients. Nat. Clim. Change, 9, 959-963.

Burrows, M.T., Schoeman, D.S., Buckley, L.B., Moore, P., Poloczanska, E.S., Brander, K.M., et al., 2011. The pace of shifting climate in marine and terrestrial ecosystems. Science, 334, $652-655$.

Bussotti, S., Di Franco, A., Bianchi, C.N., Chevaldonné, P., Egea, L., Fanelli, E., et al., 2018. Fish mitigate trophic depletion in marine cave ecosystems. Sci. Rep., 8, 9193.

Bussotti, S., Di Franco, A., Francour, P., Guidetti, P., 2015. Fish Assemblages of Mediterranean Marine Caves. PLoS ONE, 10, e0122632.

Butchart, S.H.M., Walpole, M., Collen, B., Van Strien, A., Scharlemann, J.P.W., Almond, R.E.A., Baillie, J.E.M., et al., 2010. Global biodiversity: Indicators of recent declines. Science, 328, $1164-1168$.

Canessa, M., Bavestrello, G., Bo, M., Trainito, E., Panzalis, P., Navone, A., et al., 2020. Coralligenous assemblages differ between limestone and granite: A case study at the Tavolara-Punta Coda Cavallo Marine Protected Area (NE Sardinia, Mediterranean Sea). Reg. Stud. Mar. Sci., 35, 101159.

Capdevila, P., Linares, C., Aspillaga, E., Lluís, Ribera, Hereu, B., 2018. Effective dispersal and density-dependence in mesophotic macroalgal forests: insights from the Mediterranean species Cystoseira zosteroides. PLoS ONE, 13, e0191346.

Cardone, F., Corriero, G., Longo, C., Mercurio, M., Tarantini, S.O., Gravina, M.F., et al., 2020. Massive bioconstructions built by Neopycnodonte cochlear (Mollusca, Bivalvia) in a mesophotic environment in the central Mediterranean Sea. Sci. Rep., 10, 1-16.

Cattaneo-Vietti, R., Bo, M., Cannas, R., Cau, A., Follesa, C., Meliadò, E., et al., 2016. An overexploited Italian treasure: past and present distribution and exploitation of the precious red coral Corallium rubrum (L., 1758) (Cnidaria: Anthozoa). Ital. J. Zool., 83, 443-455. 
Cebrian, E., Rodríguez-Prieto, C., 2012. Marine invasion in the Mediterranean Sea: the role of abiotic factors when there is no biological resistance. PLoS ONE, 7, e31135.

Ceccherelli, G., Pinna, S., Cusseddu, V., Bulleri, F., 2014. The role of disturbance in promoting the spread of the invasive seaweed Caulerpa racemosa in seagrass meadows. Biol. Invasions, $16,2737-2745$.

Cerrano, C., Bastari, A., Calcinai, B., Di Camillo, C., Pica, D., Puce, S., et al., 2019. Temperate mesophotic ecosystems: gaps and perspectives of an emerging conservation challenge for the Mediterranean Sea. Eur. Zool. J., 86, 370-388.

Cerrano, C., Bavestrello, G., Bianchi, C.N., Calcinai, B., Cattaneo-Vietti, R., Morri, C., et al., 2001. The role of sponges bioerosion in Mediterranean coralligenous accretion. In: Faranda, F.M., Guglielmo, L., Spezie G. (Eds), Mediterranean Ecosystems, Springer, Milano, 235-240.

Cerrano, C., Danovaro, R., Gambi, C., Pusceddu, A., Riva, A., Schiaparelli, S., 2010. Gold coral (Savalia savaglia) and gorgonian forests enhance benthic biodiversity and ecosystem functioning in the mesophotic zone. Biodiv. Conserv., 19, 153-167.

Chappuis, E., Terradas, M., Cefalì, M.E., Mariani, S., Ballesteros, E., 2014. Vertical zonation is the main distribution pattern of littoral assemblages on rocky shores at a regional scale. Estuar. Coast. Shelf Sci., 147, 113-122.

Cheminée, A., Sala, E., Pastor, J., Bodilis, P., Thiriet, P., Mangialajo, L. et al., 2013. Nursery value of Cystoseira forests for Mediterranean rocky reef fishes. J. Exp. Mar. Biol. Ecol., 442, 7079.

CINEA, 2021. European Climate, Infrastructure and Environment Executive Agency (CINEA). Sustainable criteria for the blue economy - Main report. Publications Office of the European Union, Luxembourg, 69 pp.

Claudet, J., Fraschetti, S., 2010. Human-driven impacts on marine habitats: A regional metaanalysis in the Mediterranean Sea. Biol. Conserv., 143, 2195-2206. 
Claudet, J., Loiseau, C., Pebayle, A., 2021. Critical gaps in the protection of the second largest exclusive economic zone in the world. Mar. Pol., 124, 104379.

Claudet, J., Loiseau, C., Sostres, M., Zupan, M., 2020. Underprotected marine protected areas in a global biodiversity hotspot. One Earth, 2, 380-384.

Clayton, M.N., 1992. Propagules of marine macroalgae: structure and development. Br. Phycol. J., 27, 219-232.

Coelho, F.J.R.C., Santos, A.L., Coimbra, J., Almeida, A., Cunha, Â., Cleary, D.F.R., et al., 2013. Interactive effects of global climate change and pollution on marine microbes: the way ahead. Ecol. Evol., 3, 1808-1818.

Cole, M., Lindeque, P., Halsband, C., Galloway, T.S., 2011. Microplastics as contaminants in the marine environment: A review. Mar. Pollut. Bull., 62, 2588-2597.

Coleman, M.A., Wernberg, T., 2020. The silver lining of extreme events. Trends Ecol. Evol., 35, $1065-1067$.

Coll, M., Piroddi, C., Albouy, C., Lasram, F.B., Cheung, W.W.L., Christensen, V., et al., 2012. The Mediterranean Sea under siege: spatial overlap between marine biodiversity, cumulative threats and marine reserves. Global Ecol. Biogeogr., 21, 465-480.

Coll, M., Piroddi, C., Steenbeek, J., Kaschner, K., Ben Rais Lasram, F., Aguzzi, J., et al., 2010. The Biodiversity of the Mediterranean Sea: Estimates, Patterns, and Threats. PLoS ONE, 5, e11842.

Colletti, A., Savinelli, B., Di Muzio, G., Rizzo, L., Tamburello, L., Fraschetti, S., et al., 2020. The date mussel Lithophaga lithophaga: Biology, ecology and the multiple impacts of its illegal fishery. Sci. Total Environ., 744, 140866.

Colloca, F., Scarcella, G., Libralato, S., 2017. Recent trends and impacts of fisheries exploitation on Mediterranean stocks and ecosystems. Front. Mar. Sci., 4, 244. 
COM/2012/0494. Communication from the Commission to the European Parliament, the Council, the European Economic and Social Committee and the Committee of the Regions. Blue Growth opportunities for marine and maritime sustainable growth /Final.

Coppa, S., De Lucia, G. A., Massaro, G., Camedda, A., Marra, S., Magni, P., et al., 2016. Is the establishment of MPAs enough to preserve endangered intertidal species? The case of Patella ferruginea in Mal di Ventre Island (W Sardinia, Italy). Aquat. Conserv. Mar. Freshw. Ecosyst., 26, 623-638.

Coppejans, E., 1980. Phytosociological studies on Mediterranean Algal Vegetation: rocky surfaces of the photophilic infralittoral zone. In: Price, J.H., Irvine, D.E.G., Farnham, W.F. (Eds), The shore environment, 2: Ecosystems, Academic Press, London, 371-393.

Corriero, G., Pierri, C., Mercurio, M., Marzano, C. N., Tarantini, S. O., Gravina, M. F., et al., 2019. A Mediterranean mesophotic coral reef built by non-symbiotic scleractinians. Sci. Rep., 9, $1-17$.

Cramer, W., Guiot, J., Fader, M., Garrabou, J., et al. (2018). Climate change and interconnected risks to sustainable development in the Mediterranean. Nat. Clim. Change, 8, 972-980. D’Onghia, G., Calculli, C., Capezzuto, F., Carlucci, R., Carluccio, A., Grehan, A., et al., 2017. Anthropogenic impact in the Santa Maria di Leuca cold-water coral province (Mediterranean Sea): observations and conservation straits. Deep Sea Res. II, 145, 87-101. de Caralt, S., Verdura, J., Vergés, A., Ballesteros, E., Cebrian, E., 2020. Differential effects of pollution on adults and recruits of a canopy-forming alga: implications for population viability under low pollutant levels. Sci. Rep., 10, 17825.

De La Fuente, G., Asnaghi, V., Chiantore, M., Thrush, S., Povero, P., Vassallo, P., et al., 2019a. The effect of Cystoseira canopy on the value of midlittoral habitats in NW Mediterranean, an emergy assessment. Ecol. Model., 404, 1-11. 
De La Fuente, G., Chiantore, M., Asnaghi, V., Kaleb, S., Falace, A., 2019b. First ex situ outplanting of the habitat-forming seaweed Cystoseira amentacea var. stricta from a restoration perspective. PeerJ, 7, 1-16.

de la Torriente, A., Aguilar, R., González-Irusta, J.M., Blanco, M., Serrano, A., 2020. Habitat forming species explain taxonomic and functional diversities in a Mediterranean seamount. Ecol. Ind., 118, 106747.

Darmaraki, S., Somot, S., Sevault, F., Nabat, P., 2019. Past variability of Mediterranean Sea marine heatwaves. Geophys. Res. Lett., 46, 9813-9823.

de Ville d'Avray, L.T., Ami, D., Chenuil, A., David, R., Féral, J.-P., 2019. Application of the ecosystem service concept at a small-scale: The cases of coralligenous habitats in the Northwestern Mediterranean Sea. Mar. Pollut. Bull., 138, 160-170.

Di Franco, A., Plass-Johnson, J.G., Di Lorenzo, M., Meola, B., Claudet, J., Gaines, S.D., 2018. Linking home ranges to protected area size: The case study of the Mediterranean Sea. Biol. Conserv., 221, 175-181.

Di Franco, E., Di Franco, A., Calò, A., Di Lorenzo, M., Mangialajo, L., Bussotti, S., et al., 2021. Inconsistent relationships among protection, benthic assemblage, habitat complexity and fish biomass in Mediterranean temperate rocky reefs. Ecol. Ind., 128, 107850.

Dimitriadis, C., Galanidi, M., Zenetos, A., Corsini-Foka, M., Giovos, I., Karachle, P. K., et al., 2020. Updating the occurrences of Pterois miles in the Mediterranean Sea, with considerations on thermal boundaries and future range expansion. Medit. Mar. Sci., 21, 6269.

Dimitriadis, C., Fournari-Konstantinidou, I., Sourbès, L., Koutsoubas, D., Katsanevakis, S., 2021. Long term interactions of native and invasive species in a marine protected area suggest complex cascading effects challenging conservation outcomes. Diversity, 13, 71.

Donohue I., Hillebrand H., Montoya J.M., Petchey O.L., Pimm S.L., Fowler M.S. et al., 2016. Navigating the complexity of ecological stability. Ecol. Lett., 19, 1172-1185. 
European Environment Agency, 2006. The changing faces of Europe's coastal areas. EEA Report n. 6, $107 \mathrm{pp}$.

Fa, D.A., 2008. Effects of tidal amplitude on intertidal resource availability and dispersal pressure in prehistoric human coastal populations: the Mediterranean-Atlantic transition. Quat. Sci. Rev., 27, 2194-2209.

Fabbri, E., Franzellitti, S., 2016. Human pharmaceuticals in the marine environment: focus on exposure and biological effects in animal species. Environ. Toxicol. Chem., 35, 799-812.

Falace, A., Kaleb, S., De La Fuente, G., Asnaghi, V., Chiantore, M., 2018. Ex situ cultivation protocol for Cystoseira amentacea var. stricta (Fucales, Phaeophyceae) from a restoration perspective. PLoS ONE, 13, e0193011.

Fanelli, G., Piraino, S., Belmonte, G., Geraci, S., Boero, F., 1994. Human predation along Apulian rocky coasts (SE Italy): desertification caused by Lithophaga lithophaga (Mollusca) fisheries. Mar. Ecol. Prog. Ser., 110, 1-8.

Felline, S., Caricato, R., Cutignano, A., Gorbi, S., Lionetto, M.G., Mollo, E., et al., 2012. Subtle effects of biological invasions: cellular and physiological responses of fish eating the exotic Pest Caulerpa racemosa. PLoS ONE, 7, e38763.

Felline, S., Mollo, E., Cutignano, A., Grauso, L., Andaloro, F., Castriota, L., et al., 2017. Preliminary observations of caulerpin accumulation from the invasive Caulerpa cylindracea in native Mediterranean fish species. Aquat. Biol., 26, 27-31.

Ferrà, C., Tassetti, A.N., Grati, F., Pellini, G., Polidori, P., Scarcella, G., et al., 2018. Mapping change in bottom trawling activity in the Mediterranean Sea through AIS data. Mar. Pol., $94,275-281$.

Ferranti, M.P., Guallart, J., Cortella, V., Terenziani, G., Chiantore, M., 2021. Are there life-history constraints on restoration of the endangered limpet Patella ferruginea (Mollusca, Gastropoda) in the northern Mediterranean Sea? Aquat. Conserv. Mar. Freshw. Ecosyst., doi.org/10.1002/aqc.3571. 
Ferretti, F., Myers, R.A., Serena, F., Lotze, H., 2008. Loss of large predatory sharks from the Mediterranean Sea. Conserv. Biol., 22, 952-964.

Font, T., Lloret, J., 2014. Biological and ecological impacts derived from recreational fishing in Mediterranean coastal areas. Rev. Fish. Sci. Aq., 22, 73-85.

Fossi, M.C., Vlachogianni, T., Galgani, F., Degli Innocenti, F., Zampetti, G., Leone, G., 2020. Assessing and mitigating the harmful effects of plastic pollution: the collective multistakeholder driven Euro-Mediterranean response. Ocean Coast. Manage., 184, 105005.

Fraschetti S., Pipitone C., Mazaris A.D., Rilov G., Badalamenti F., Bevilacqua S., et al., 2018. Light and shade in marine conservation across European and Contiguous Seas. Front. Mar. Sci., $5,420$.

Fraschetti, S., Terlizzi, A., Bevilacqua, S., Boero, F., 2006. The distribution of hydroids (Cnidaria, Hydrozoa) from micro- to macro-scale: spatial patterns on habitat-forming algae. J. Exp. Mar. Biol. Ecol., 339, 148-158.

Furlani, S., Pappalardo, M., Gomez-Pujol, L., Chelli, A., 2014. The rock coast of the Mediterranean and Black Seas. In: Kennedy, D.M., Stephenson, W.J., Naylor, L.A. (Eds), Rock Coast Geomorphology: A Global Synthesis. Geological Society, London Memoirs, 40, 89-123.

Galil, B., Boero, F., Fraschetti, S., Piraino, S., Campbell, M., Hewitt, C., et al., 2015. The enlargement of the Suez Canal and introduction of non-indigenous species to the Mediterranean Sea. Limnol. Oceanogr. Bull., 24, 43-45.

Garrabou, J., Coma, R., Bensoussan, N., Bally, M., Chevaldonne, P., Cigliano, M., et al., 2009. Mass mortality in Northwestern Mediterranean rocky benthic communities: effects of the 2003 heat wave. Global Change Biol., 15, 1090-1103.

Garrabou, J., Gómez-Gras, D., Ledoux, J.B., Linares, C., Bensoussan, N., López-Sendino, P., et al., 2019. Collaborative database to track mass mortality events in the Mediterranean Sea. Front. Mar. Sci., 6, 707. 
Garrabou, J., Ledoux, J.B., Bensoussan, N., Gómez-Gras, D., Linares, C. in press, Sliding towards the collapse of Mediterranean coastal marine rocky ecosystems, Josep G. Canadell and Robert B. Jackson (Eds): Ecosystem Collapse and Climate Change, Ecological Studies, Vol. 241, Chapter 11.

Gattuso, J.-P., Magnan, A., Billé, R., Cheung, W., Howes, E., Joos, F., et a., 2015. Contrasting futures for ocean and society from different anthropogenic $\mathrm{CO}_{2}$ emissions scenarios. Science, 349, aac4722.

Geraldi, N.R., Anton, A., Santana-Garcon, J., Bennett, S., Marbà, N., Lovelock, C.E., et al., 2020. Ecological effects of non-native species in marine ecosystems relate to co-occurring anthropogenic pressures. Global Change Biol., 26, 1248-1258.

Giallongo, G., Douek, J., Harbuzov, Z., Galil, B.S., Rinkevich, B., 2021. Long-term changes in population genetic features of a rapidly expanding marine invader: implication for invasion success. Biol. Invasions, doi: 10.1007/s10530-021-02521-8.

Giaccone, G., 1972. Struttura, ecologia e corologia dei popolamenti a laminarie dello stretto di Messina e del mare di Alboran. Memorie di Biologia Marina e di Oceanografia, 2, 37-59.

Giakoumi, S., Katsanevakis, S., Albano, P.G., Azzurro, E., Cardoso, A.C., Cebrian, E., et al., 2019. Management priorities for marine invasive species. Sci. Tot. Env., 688, 976-982.

Giakoumi, S., Scianna, C., Plass-Johnson, J., Micheli, F., Grorud-Colvert, K., Thiriet, P., et al., 2017. Ecological effects of full and partial protection in the crowded Mediterranean Sea: a regional meta-analysis. Sci. Rep., 7, 8940.

Gianni, F., Bartolini, F., Airoldi, L., Ballesteros, E., Francour, P., Guidetti, P., et al., 2013. Conservation and restoration of marine forests in the Mediterranean Sea and the potential role of Marine Protected Areas. Adv. Oceanogr. Limnol., 4, 83.

Gianni, F., Bartolini, F., Pey, A., Laurent, M., Martins, G.M., Airoldi, L., et al., 2017. Threats to large brown algal forests in temperate seas: the overlooked role of native herbivorous fish. Sci. Rep., 7, 6012. 
Gissi, E., Manea, E., Mazaris, A.D., Fraschetti, S., Almpanidou, V., Bevilacqua, S., et al., 2021. A review of the combined effects of climate change and other human stressors on the marine environment. Sci. Tot. Env., 755, 142564.

Gonzáles, A.V., Beltrán, J., Flores, V., Santelices, B., 2015. Morphological convergence in the inter-holdfast coalescence process among kelp and kelp-like seaweeds (Lessonia, Macrocystis, Durvillaea). Phycologia, 54, 283-291.

Gorbi, S., Giuliani, M.E., Pittura, L., d'Errico, G., Terlizzi, A., Felline, S., et al. 2014. Could molecular effects of Caulerpa racemosa metabolites modulate the impact on fish populations of Diplodus sargus? Mar. Environ. Res., 96, 2-11.

Green, S.J., Dulvy, N.K., Brooks, A.M., Akins, J.L., Cooper, A.B., Miller, S., et al., 2014. Linking removal targets to the ecological effects of invaders: a predictive model and field test. Ecol. Appl., 24, 1311-1322.

Gribben, P.E., Angelini, C., Altieri, A.H., Bishop, M.J., Thomsen, M.S. Bulleri, F., (2019). Facilitation cascades in marine ecosystems: A synthesis and future directions. In: Hawkins, S.J., Allcock, A.L., Bates, A.E., Firth, L.B., Smith, I.P., Swearer, S.E., et al., (Eds), Oceanography and Marine Biology. Taylor and Francis, Boca Raton, FL, USA, 127-168. Gribben, P.E., Thomas, T., Pusceddu, A., Bonechi, L., Bianchelli. S., Buschi, E., et al., 2018. Below-ground processes control the success of an invasive seaweed. J. Ecol., 106, 20822095.

Guarnieri, G., Bevilacqua, S., Figueras, N., Tamburello, L., Fraschetti, S., 2020. Large-scale sea urchin culling drives the reduction of subtidal barren grounds in the Mediterranean Sea. Front. Mar. Sci., 7, 519.

Guarnieri, G., Terlizzi, A., Bevilacqua, S., Fraschetti, S., 2012. Increasing heterogeneity of sensitive assemblages as a consequence of human impact in submarine caves. Mar. Biol., 159, 11551164 
Gubbay, S., Sanders, N., Haynes, T., Janssen, J.A.M., Rodwell, J.R., Nieto, A., et al., 2016. European Red List of Habitats. Part 1: Marine Habitats. Luxembourg: Publications Office of the European Union.

Guidetti, P., 2006. Marine reserves reestablish lost predatory interactions and cause community changes in rocky reefs. Ecol. Appl., 16, 963-976.

Guidetti, P., Baiata, P., Ballesteros, E., Di Franco, A., Hereu, B., Macpherson, E., et al., 2014. Large-scale assessment of Mediterranean marine protected areas effects on fish assemblages. PLoS ONE, 9, e91841.

Guidetti, P., Bianchi, C.N., Chiantore, M., Schiaparelli, S., Morri, C., Cattaneo-Vietti, R., 2004. Living on the rocks: substrate mineralogy and the structure of subtidal rocky substrate communities in the Mediterranean Sea. Mar. Ecol. Progr. Ser., 274, 57-68.

Guidetti, P., 2011. The destructive date-mussel fishery and the persistence of barrens in Mediterranean rocky reefs. Mar. Pollut. Bull., 62, 691-695.

Guidetti, P., Fanelli, G., Fraschetti, S., Terlizzi, A., Boero, F., 2002. Coastal fish indicate humaninduced changes in the Mediterranean littoral. Mar. Environ. Res., 53, 77-94.

Guidetti, P., Micheli, F., 2011. Art serving marine conservation. Front. Ecol. Environ., 9, 374-375.

Guidetti, P., Sala, E., 2007. Community-wide effects of marine reserves in the Mediterranean Sea. Mar. Ecol. Prog. Ser., 335, 43-56.

Hallegraeff, G., Enevoldsen, H., Zingone, A., 2021. Global harmful algal bloom status reporting. Harm. Algae, 102, 101992.

Halpern, B.S., Walbridge, S., Selkoe, K.A., Kappel, C.V., Micheli, F., D’agrosa, C., et al., 2008. A global map of human impact on marine ecosystems. Science, 319, 948-952.

Halpern, B.S., Frazier, M., Afflerbach, J., Lowndes, J.S., Micheli, F., O’Hara, C., et al., 2019. Recent pace of change in human impact on the world's ocean. Sci. Rep., 9, 11609.

Hampe, A., Petit, R.J., 2005. Conserving biodiversity under climate change: the rear edge matters. Ecol Lett., 8, 461-467. 
Harmelin-Vivien, M.L., Bitar, G., Harmelin, J.G., Monestiez, P., 2005. The littoral fish community of the Lebanese rocky coast (eastern Mediterranean Sea) with emphasis on Red Sea immigrants. Biol. Invasions, 7, 625-637.

Helmuth, B., Harley, C.D.G., Halpin, P.M., O'Donnell, M., Hofmann, G.E., Blanchette, C.A., 2002. Climate change and latitudinal patterns of intertidal thermal stress. Science, 298, 10151017.

Hereu, B., 2006. Depletion of palatable algae by sea urchins and fishes in a Mediterranean subtidal community. Mar. Ecol. Progr. Ser., 313, 95-103.

Hereu, B., Zabala, M., Sala, E., 2008. Multiple controls of community structure and dynamics in a sublittoral marine environment. Ecology, 89, 3423-3435.

Hillebrand, H., Langenheder, S., Labret, K., Lindström, E., Östman, Ö., Striebel, M., 2018. Decomposing multiple dimensions of stability in global change experiments. Ecol. Lett., 21, $21-30$.

Hoegh-Guldberg, O., et al., 2015. Reviving the Ocean Economy: the case for action - 2015. WWF International, Gland, Switzerland., Geneva, 60 pp.

Holling, C.S., 2001. Understanding the complexity of economic, ecological, and social systems. Ecosystems, 4, 390-405.

Horta e Costa, B., Claudet, J., Franco, G., Erzini, K., Caro, A., Gonçalves, E.J., 2016. A regulationbased classification system for Marine Protected Areas (MPAs). Mar. Pol., 72, 192-198.

Hughes, T.P., Graham, N.A., Jackson, J.B., Mumby, P.J., Steneck, R.S., 2010. Rising to the challenge of sustaining coral reef resilience. Trends Ecol. Evol., 25, 633-642.

Ingrosso, G., Abbiati, M., Badalamenti, F., Bavestrello, G., Belmonte, G., Cannas, R., et al., 2018. Mediterranean Bioconstructions Along the Italian Coast. Adv. Mar. Biol., 79, 61-136.

Ivesa, L., Djakovac, T., Devescovi, M., 2016. Long-term fluctuations in Cystoseira populations along the west Istrian Coast (Croatia) related to eutrophication patterns in northern Adriatic Sea. Mar. Pollut. Bull., 106, 162-173. 
Israel, A., Einav, R., 2017. Alien seaweeds from the Levant basin (Eastern Mediterranean Sea), with emphasis to the Israeli shores. Israel J. Plant Sci., 64, 99-110.

Johnson, D.E., Kenchington, E.L., 2019. Should potential for climate change refugia be mainstreamed into the criteria for describing EBSAs? Conserv. Lett., 12, e12634.

Johnson, L., Galliart, M., Alsdurf, J., Maricle, B.R., Baer, S.G., Bello, N.M., et al., 2021. Reciprocal transplant gardens as gold standard to detect local adaptation in grassland species: New opportunities moving into the 21st century. J. Ecol., doi.org/10.1111/13652745.13695 .

Kapsenberg, L., Alliouane, S., Gazeau, F., Mousseau, L., Gattuso, J.P., 2017. Coastal ocean acidification and increasing total alkalinity in the northwestern Mediterranean Sea. Ocean Science, 13, 411-426.

Katsanevakis, S., Coll, M., Fraschetti, S., Giakoumi, S., Goldsborough, D., Mačić, V., et al., 2020. Twelve Recommendations for Advancing Marine Conservation in European and Contiguous Seas. Front. Mar. Sci., 7, 565968.

Katsanevakis, S., Coll, M., Piroddi, C., Steenbeek, J., Ben Rais Lasram, F., Zenetos, A., et al., 2014. Invading the Mediterranean Sea: biodiversity patterns shaped by human activities. Front. Mar. Sci., 1, 32.

Katsanevakis, S., Poursanidis, D., Issaris, Y., Panou, A., Petza, D., Vassilopoulou, V., et al., 2011. "Protected" marine shelled molluscs: thriving in Greek seafood restaurants. Medit. Mar. Sci., 12, 429-438.

Klein, J., Verlaque, M. 2008. The Caulerpa racemosa invasion: A critical review. Mar. Poll. Bull., $56,205-225$.

Krumhansl, K.A., Okamoto, D.K., Rassweiler, A., Novak, M., Bolton, J.J., Cavanaugh, K.C., et al., 2016. Global patterns of kelp forest change over the past half-century. Proc. Natl. Acad. Sci. USA, 113, 13785-13790. 
Lastras, G., Canals, M., Ballesteros, E., Gili, J.M., Sanchez-Vidal, A., 2016. Cold-water corals and anthropogenic impacts in La Fonera submarine canyon head, Northwestern Mediterranean Sea. PloS ONE, 11, e0155729.

Lejeusne, C., Chevaldonné, P., Pergent-Martini, C., Boudouresque, C.F., Perez, T., 2010. Climate change effects on a miniature ocean: the highly diverse, highly impacted Mediterranean Sea. Trends Ecol. Evol., 25, 250-60.

Li, W.C., Tse, H.F., Fok, L., 2016. Plastic waste in the marine environment: a review of sources, occurrence and effects. Sci. Total Environ., 566-567, 333-349.

Linares, C., Vidal, M., Canals, M., Kersting, D.K., Amblass, D., Aspillaga, E., et al., 2015. Persistent natural acidification drives major distribution shifts in marine benthic ecosystems. Proc. Royal Soc. B, 282, 20150587.

Lubchenco, J., Palumbi, S.R., Gaines, S.D., Andelman, S., 2003. Plugging a hole in the ocean: the emerging science of marine reserves. Ecol. Appl., 13, S3-S7.

Mačić, V., Albano, P. G., Almpanidou, V., Claudet, J., Corrales, X., Essl, F., et al., 2018. Biological invasions in conservation planning: a global systematic review. Front. Mar. Sci., 5, 178.

Mack, R.N., Simberloff, D., Lonsdale, W.M., Evans, H., Clout, M., Bazzaz, F.A., 2000. Biotic invasions: Causes, epidemiology, global consequences, and control. Ecol. Appl., 10, 689710.

Maggi, E., Bertocci, I., Vaselli, S., Benedetti-Cecchi, L., 2009. Effects of changes in number, identity and abundance of habitat-forming species on assemblages of rocky seashores, Mar. Ecol. Prog. Ser., 381, 39-49.

Mamo, L.T., Wood, G., Wheeler, D., Kelaher, B.P, Coleman, M.A., 2021. Conservation genomics of a critically endangered brown seaweed. J. Phycol., doi: 10.1111/jpy.13177.

Mangialajo, L., Chiantore, M., Cattaneo-Vietti, R., 2008. Loss of fucoid algae along a gradient of urbanisation, and structure of benthic assemblages. Mar. Ecol. Progr. Ser., 358, 63-74. 
Mangialajo, L., Ganzin, N., Accoroni, S., Asnaghi, V., Blanfuné, A., Cabrini, M., et al., 2011. Trends in Ostreopsis proliferation along the Northern Mediterranean coasts. Toxicon, 57, $408-420$.

Martellini, T., Guerranti, C., Scopetani, C., Ugolini, A., Chelazzi, D., Cincinelli, A., 2018. A snapshot of microplastics in the coastal areas of the Mediterranean Sea. Trends Anal. Chem., 109, 173-179.

Martin, C.S., Giannoulaki, M., De Leo, F., Scardi, M., Salomidi, M., Knittweis, L., et al., 2014. Coralligenous and maërl habitats: predictive modelling to identify their spatial distributions across the Mediterranean Sea. Sci. Rep., 4, 5073.

Martin, S., Gattuso, J.P., 2009. Response of Mediterranean coralline algae to ocean acidification and elevated temperature. Glob. Change Biol., 15, 2089-2100.

Micheli, F., Benedetti-Cecchi, L., Gambaccini, S., Bertocci, I., Borsini, C., Osio, G.C., et al., 2005. Cascading human impacts, marine protected areas, and the structure of Mediterranean reef assemblages. Ecol. Monogr., 75, 81-102.

Micheli, F., Saenz-Arroyo, A., Greenley, A., Vazquez, L., Montes, J.A.E., Rossetto, M., et al., 2012. Evidence that marine reserves enhance resilience to climatic impacts. PloS ONE, 7, e40832.

Micheli, F., Halpern, B.S., Walbridge, S., Ciriaco, S., Ferretti, F., Fraschetti, S., et al., 2013. Cumulative human impacts on Mediterranean and Black Sea marine ecosystems: assessing current pressures and opportunities. PLoS ONE, 8, e79889.

Milanese, M., Sarà, A., Sarà, G., Murray, J., 2011. Climate change, marine policy and the valuation of Mediterranean intertidal ecosystems. Chem. Ecol., 27, 95-105.

Milazzo, M., Badalamenti, F., Riggio, S., Chemello, R., 2004. Patterns of algal recovery and smallscale effects of canopy removal as a result of human trampling on a Mediterranean rocky shallow community. Biol. Conserv., 117, 191-202. 
Milazzo, M., Mirto, S., Domenici, P., Gristina, M., 2013. Climate change exacerbates interspecific interactions in sympatric coastal fishes. J. Anim. Ecol., 82, 468-477.

Milazzo, M., Rodolfo-Metalpa, R., Chan, V., Fine, M., 2014. Ocean acidification impairs vermetid reef recruitment. Sci. Rep., 4, 4189.

Mineur, F., Arenas, F., Assis, J., Davies, A.J., Engelen, AH., Fernandes, F., et al., 2015. European seaweeds under pressure: Consequences for communities and ecosystem functioning. J. Sea Res., 98, 91-108.

Montero-Serra, I., Linares, C., Doak, D.F., Ledoux, J.B., Garrabou, J., 2018. Strong linkages between depth, longevity and demographic stability across marine sessile species. Proc. Royal Soc. B., 285, 20172688.

Morganti, T., Coma, R., Yahel, G., Ribes, M., 2017. Trophic niche separation that facilitates coexistence of high and low microbial abundance sponges is revealed by in situ study of carbon and nitrogen fluxes. Limnol. Oceanog., 62, 1963-1983.

Musco, L., Prada, F., D’Anna, G., Galasso, N.M., Pipitone, C., Vega Fernández, T., et al., 2017. Turning casualty into opportunity: fragmenting dislodged colonies is effective for restoring reefs of a Mediterranean endemic coral. Ecol. Eng., 98, 206-212.

Navarro, L., Ballesteros, E., Linares, C., Hereu, B., 2011. Spatial and temporal variability on deepwater algal assemblages in the Northwestern Mediterranean: insights into the effects of an exceptional storm. Estuar. Coast. Shelf Sci., 95, 52-58.

Occhipinti-Ambrogi, A., 2021. Biopollution by invasive marine non-indigenous species: A review of potential adverse ecological effects in a changing climate. Int. J. Env. Res. Publ. Health, 18,4268 .

O’Leary, J.K., Micheli, F., Airoldi, L., Boch, C., De Leo, G., Elahi, R., et al., 2017. The resilience of marine ecosystems to climatic disturbances. Bioscience, 67, 208-220. 
Orlando-Bonaca, M., Pitacco, V., Slavinec, P., Šiško, M., Makovec, T., Falace, A., 2021. First restoration experiment for Gongolaria barbata in slovenian coastal waters. What can go wrong? Plants, 10, 1-17.

Pagès-Escolà, M., Linares, C., Gómez-Gras, D., Medrano, A., Hereu, B., 2020. Assessing the effectiveness of restoration actions for Bryozoans: The case of the Mediterranean Pentapora fascialis. Aquat. Conserv. Mar. Freshw. Ecosyst., 30, 8-19.

Peleg, O., Guy-Haim, T., Yeruham, E., Silverman, J., Rilov, G., 2020. Tropicalization may invert trophic state and carbon budget of shallow temperate rocky reefs. J. Ecol., 108, 844-854.

Perkol-Finkel, S., Ferrario, F., Nicotera, V., Airoldi, L, 2012. Conservation challenges in urban seascapes: Promoting the growth of threatened species on coastal infrastructures. J. Appl. Ecol., 49, 1457-1466.

Piazzi, L., Balata, D., Bulleri, F., Gennaro, P., Ceccherelli, G., 2016. The invasion of Caulerpa cylindracea in the Mediterranean: the known, the unknown and the knowable. Mar. Biol., $163,161$.

Piazzi, L., Bonaviri, C., Castelli, A., Ceccherelli, G., Costa, G., Curini-Galletti, M., et al., 2018. Biodiversity in canopy-forming algae: Structure and spatial variability of the Mediterranean Cystoseira assemblages. Estuar. Coast. Shelf Sci., 207, 132-141.

Piccardo, M., Renzi, M., Terlizzi, A., 2020. Nanoplastics in the oceans: theory, experimental evidence and real world. Mar. Pollut. Bull., 157, 111317.

Pinnegar, J., Polunin, N.V.C., 2006. Planktivorous damselfish support significant nitrogen and phosphorus fluxes to Mediterranean reefs. Mar. Biol., 148, 1089-1099.

Pisano, A., Marullo, S., Artale, V., Falcini, F., Yang, C., Leonelli, F.E., et al., 2020. New evidence of Mediterranean climate change and variability from sea surface temperature observations. Remote Sens., 2020, 12, 132.

Pola, L., Calcinai, B., Pica, D., Di Camillo, C.G., Martin, D., Cerrano, C., 2020. Updating the current knowledge on the relationships between Haplosyllis chamaeleon Laubier, 1960 
(Annelida, Syllidae) and Paramuricea clavata (Risso, 1826) (Cnidaria, Plexauridae) in the Mediterranean Sea. Mar. Biodivers., 50, 1-11.

Poloczanska, E.S., Brown, C.J., Sydeman, W.J., Kiessling, W., Schoeman, D.S., Moore, P.J., et al., Global imprint of climate change on marine life. Nat. Clim. Change, 3, 919-925.

Ponti, M., Turicchia, E., Ferro, F., Cerrano, C., Abbiati, M., 2018. The understorey of gorgonian forests in mesophotic temperate reefs. Aquat. Conserv. Mar. Freshw. Ecosys., 28, 11531166.

Prato, G., Guidetti, P., Bartolini, F., Mangialajo, L., Francour, P., 2013. The importance of highlevel predators in marine protected area management: Consequences of their decline and their potential recovery in the Mediterranean context. Adv. Oceanogr. Limnol., 4, 176-193.

Rattray, A., Andrello, M., Asnaghi, V., Bevilacqua, S., Bulleri, F., Cebrian, E., et al., 2016.

Geographic distance, water circulation and environmental conditions shape the biodiversity of Mediterranean rocky coasts. Mar. Ecol. Progr. Ser., 553, 1-11.

Raniello, R., Mollo, E., Lorenti, M., Gavagnin, M., 2007. Phytotoxic activity of caulerpenyne from the Mediterranean invasive variety of Caulerpa racemosa: A potential allelochemical. Biol. Invasions, 9, 361-368.

Rastelli, E., Petani, B., Corinaldesi, C., Dell'Anno, A., Martire, M. L., Cerrano, C., et al., 2020. A high biodiversity mitigates the impact of ocean acidification on hard-bottom ecosystems. Sci. Rep., 10, 1-13.

Renanel, R.S.M., Kiflawi, M., Friedlander, A.M., Belmaker, J., 2018. Habitat utilization by an invasive herbivorous fish (Siganus rivulatus) in its native and invaded range. Biol. Invasions, 20, 3499-3512.

Rilov, G., Galil, B. 2009. Marine bioinvasions in the Mediterranean Sea - history, distribution and ecology. In: Rilov, G., Crooks, J.A. (Eds). Biological Invasions in Marine Ecosystems: Ecological, Management, and Geographic Perspectives. Ecological Studies Series. Springer, Heidelberg, Germany. pp 549-576. 
Rilov, G., Fraschetti, S., Gissi, E., Pipitone, C., Badalamenti, F., Tamburello, L., et al., 2020b. A fast-moving target: achieving marine conservation goals under shifting climate and policies. Ecol. Appl., 30, e02009.

Rilov, G., Mazaris, A., Stelzenmüller, V., Helmuth, B., Wahl, M., Guy-Haim, T., et al., 2019b. Adaptive marine conservation planning in the face of climate change: what can we learn from physiological, genetic and ecological studies? Global Ecol. Conserv., 17, e00566.

Rilov, G., Peleg, O., Yeruham, E., Garval, T., Vichik, A., 2018. Alien turf: Overfishing, overgrazing and invader domination in south-eastern Levant reef ecosystems. Aquat. Conserv. Mar. Freshw. Ecosys., 28, 351-369.

Rilov, R., Peleg, O., Guy-Haim, T., 2019a. The restructuring of levant reefs by aliens, ocean warming and overfishing - implications for species interactions and ecosystem functions. In: Hawkins, S.J., Bohn, K., Firth, L.B., Williams, G.A. (Eds), Interactions in the Marine Benthos, Cambridge University Press, 214-236.

Rilov, G., Peleg, O., Guy-Haim, T., Yeruham, E., 2020a. Community dynamics and ecological shifts on Mediterranean vermetid reefs. Mar. Environ. Res., 160, 105045.

Rilov, G., David, N., Guy-Haim, T., Arav, R., Filin, S., 2021. Sea level rise can severely reduce biodiversity and community net production on rocky shores. Sci. Total Environ., doi: 10.1016/j.scitotenv.2021.148377.

Rindi, L., Dal Bello, M., Dai, L., Gore, F., Benedetti-Cecchi, L., 2017. Direct observation of increasing recovery length before collapse of a marine benthic ecosystem. Nat. Ecol. Evol., $1,0153$.

Rios Mendoza, L.M., Karapanagioti, H., Ramírez Álvarez, N., 2018. Micro(nanoplastics) in the marine environment: Current knowledge and gaps. Curr. Opin. Environ. Sci. Health, 1, 4751. 
Rizzo, L., Pusceddu, A., Stabili, L., Fraschetti, S., 2017. Potential effects of an invasive seaweed (Caulerpa cylindracea, Sonder) on sedimentary organic matter and microbial metabolic activities. Sci. Rep., 7, 12113.

Rodríguez-Prieto, C., Ballesteros, E., Boisset, F., Afonso-Carrillo, J., 2013. Guía de las macroalgas y fanerógamas marinas del Mediterráneo Occidental. Ediciones Omega, Barcelona, 656 pp.

Rotter, A., Klun, K., Francé, J., Mozetič, P., Orlando-Bonaca M., 2020. Non-indigenous species in the Mediterranean Sea: turning from pest to source by developing the 8Rs model, a new paradigm in pollution mitigation. Front. Mar. Sci., 7, 178.

Roura-Pascual, N., Leung, B., Rabitsch, W., Rutting, L., Vervoort, J., Bacher, S., et al., 2021.

Alternative futures for global biological invasions. Sustain. Sci., https://doi.org/10.1007/s11625-021-00963-6.

Sala, E., 2004. The past and present topology and structure of Mediterranean subtidal rocky-shore food webs. Ecosystems, 7, 333-340.

Sala, E., Ballesteros, E., Dendrinos, P., Di Franco, A., Ferretti, F., Foley, D., et al., 2012. The Structure of Mediterranean Rocky Reef Ecosystems across Environmental and Human Gradients, and Conservation Implications. PLoS ONE, 7, e32742.

Sala, E., Boudouresque, C.F., Harmelin-Vivien, M., 1998. Fishing, trophic cascades, and the structure of algal assemblages: Evaluation of an old but untested paradigm. Oikos, 82, 425439.

Sala, E., Kizilkaya, Z., Yildirim, D., Ballesteros, E., 2011. Alien marine fishes deplete algal biomass in the eastern Mediterranean. PLoS ONE, 6, e17356.

Salat, J., Pascual, J., Flexas, M., Chin, T.M., Vazquez-Cuervo, J., 2019. Forty-five years of oceanographic and meteorological observations at a coastal station in the NW Mediterranean: a ground truth for satellite observations. Ocean Dynam., 69, 1067.

Sant, N., Ballesteros, E., 2021. Depth distribution of canopy-forming algae of the order Fucales is related to their photosynthetic features. Mar. Ecol., 42, e12651. 
Sarà, G., Milanese, M., Prusina, I., Sarà, A., Angel, D.L., Glamuzina, B., et al., 2014. The impact of climate change on Mediterranean intertidal communities: losses in coastal ecosystem integrity and services. Reg. Environ. Change, 14, 5-17.

Savini, A., Vertino, A., Marchese, F., Beuck, L., Freiwald, A. ,2014. Mapping cold-water coral habitats at different scales within the Northern Ionian Sea (Central Mediterranean): an assessment of coral coverage and associated vulnerability. PLoS ONE, 9, e87108.

Savonitto, G., De La Fuente, G., Tordoni, E., Ciriaco, S., Srijemsi, M., Bacaro, G., et al., 2021. Addressing reproductive stochasticity and grazing impacts in the restoration of a canopyforming brown alga by implementing mitigation solutions. Aquat. Conserv. Mar. Freshw. Ecosyst., doi.org/10.1002/aqc.3555.

Scheffer, M., 2009. Critical transitions in nature and society. Princeton University Press, Princeton, $384 \mathrm{pp}$.

Sini, M., Vatikiotis, K., Thanopoulou, Z., Katsoupis, C., Maina, I., Kavadas, S., et al., 2019. Smallscale coastal fishing shapes the structure of shallow rocky reef fish in the Aegean Sea. Front. Mar. Sci., 6, 599.

Skliris, N., Sofianos, S., Gkanasos, A., Mantziafou, A., Vervatis, V., Axaopoulos, P., et al., 2012. Decadal scale variability of sea surface temperature in the Mediterranean Sea in relation to atmospheric variability. Ocean Dynam., 62, 13-30.

Soto-Navarro, J., Jordá, G., Compa, M., Alomar, C., Fossi, M.C., Deudero, S., 2021. Impact of the marine litter pollution on the Mediterranean biodiversity: A risk assessment study with focus on the marine protected areas. Mar. Pollut. Bull., 165, 112169.

Soto-Navarro, J., Jordá, G., Deudero, S., Alomar, C., Amores, A., Compa, M., 2020. 3D hotspots of marine litter in the Mediterranean: a modeling study. Mar. Pollut. Bull., 155, 111159.

Steffen, W., Richardson, K., Rockström, J., Cornell, S.E., Fetzer, I., Bennett, E.M., et al., 2015. Planetary boundaries: Guiding human development on a changing planet. Science, 347, 1259855. 
Strain, E.M.A., Steinberg, P.D., Vozzo, M., Johnston, E.L., Abbiati, M., Aguilera, M.A., et al., 2021. A global analysis of complexity-biodiversity relationships on marine artificial structures. Glob. Ecol. Biogeogr., 30, 140-153.

Strain, E.M.A., Thomson, R.J., Micheli, F., Mancuso, F.P., Airoldi, L., 2014. Identifying the interacting roles of stressors in driving the global loss of canopy-forming to mat-forming algae in marine ecosystems. Glob. Chang. Biol., 20, 3300-3312.

Teixidó, N., Casas, E., Cebrián, E., Linares, C., Garrabou, J., 2013. Impacts on coralligenous outcrop biodiversity of a dramatic coastal storm. PloS ONE, 8, e53742.

Terlizzi, A., Benedetti-Cecchi, L., Bevilacqua, S., Fraschetti, S., Guidetti, P., Anderson, M.J., 2005. Multivariate and univariate asymmetrical analyses in environmental impact assessment: a case study of Mediterranean subtidal sessile assemblages. Mar. Ecol. Prog. Ser., 289, 27-42.

Terlizzi, A., Scuderi, D., Fraschetti, S., Guidetti, P., Boero, F., 2003. Molluscs on subtidal cliffs: patterns of spatial distribution. J. Mar. Biol. Ass. UK, 83, 165-172.

Thibaut, T., Blanfuné, A, Boudouresque, C.F., Personnic, S., Ruitton, S., Ballesteros, E., et al., 2017. An ecosystem-based approach to assess the status of Mediterranean algae-dominated shallow rocky reefs. Mar. Pollut. Bull., 117, 311-329.

Thibaut, T., Blanfuné, A., Boudouresque, C.F., Verlaque, M., 2015. Decline and local extinction of Fucales in the French Riviera: The harbinger of future extinctions? Medit. Mar. Sci., 16, 206-224.

UfMS, 2017. Blue economy in the Mediterranean. The Union for the Mediterranean Secretariat, 72 pp.

UNEP-RAC/SPA, 2003. The coralligenous in the Mediterranean Sea, $82 \mathrm{pp}$.

UNEP/MAP, 2017. Mediterranean Quality Status Report, 539 pp.

Valisano, L., Notari, F., Mori, M., Cerrano, C., 2016. Temporal variability of sedimentation rates and mobile fauna inside and outside a gorgonian garden. Mar. Ecol., 37, 1303-1314. 
Van der Hal, N., Yeruham, E., Shukis, D., Rilov, G., Astrahan, P., Angel, D.L., 2019. Uptake and incorporation of PCBs by eastern Mediterranean rabbitfish that consumed microplastics. Mar. Pollut. Bull., 150, 110697.

van Vuuren, D.P., Kriegler, E., O’Neill, B.C., Ebi, K.L., Riahi, K., Carter, T.R., et al., 2014. A new scenario framework for climate change research: scenario matrix architecture. Clim. Change, 122, 373-386.

Verdura, J., Sales, M., Ballesteros, E., Cefalì, M.E., Cebrian, E., 2018. Restoration of a canopyforming alga based on recruitment enhancement: Methods and long-term success assessment. Front. Plant Sci., 9, 1-12.

Verdura, J., Santamaría, J., Ballesteros, E., Smale, D., Cefalì, M.E., Golo, R., et al., 2021. Localscale climatic refugia offer sanctuary for a habitat-forming species during a marine heatwave. J. Ecol., 109, 1758-1773.

Vergès, A., Tomas, F., Cebrian, E., Ballesteros, E., Kizilkaya, Z., Dendrinos, P., et al., 2014. Tropical rabbitfish and the deforestation of a warming temperate sea. J. Ecol., 102, 15181527.

Vezzulli, L., Pezzati, E., Huete-Stauffer, C., Pruzzo, C., Cerrano, C., 2013. 16SrDNA pyrosequencing of the Mediterranean gorgonian Paramuricea clavata reveals a link among alterations in bacterial holobiont members, anthropogenic influence and disease outbreaks. PloS ONE, 8, e67745.

Villegas-Hernández, H., Lloret, J., Muñoz, M., 2015. Reproduction, condition, and abundance of the Mediterranean bluefish (Pomatomus saltatrix) in the context of sea warming. Fish. Oceanogr., 24, 42-56.

Wernberg, T., Russell, B.D., Thomsen, M.S., Gurgel, C.F., Bradshaw, C.J., Poloczanska, E.S., et al., 2011. Seaweed communities in retreat from ocean warming. Curr. Biol., 21, 1828-1832. Wolff, C., Nikoletopoulos, T., Hinkel, J., Vafeidis, A.T., 2020. Future urban development exacerbates coastal exposure in the Mediterranean. Sci. Rep., 10, 14420. 
Wood, G., Marzinelli, E.M., Campbell, A.H., Steinberg, P.D., Vergés, A., Coleman, M.A., 2021. Genomic vulnerability of a dominant seaweed points to future-proofing pathways for Australia's underwater forests. Glob. Change Biol., 27, 2200-2212.

Yeruham, E., Rilov, G., Shpigel, M., Abelson, A., 2015. Collapse of the echinoid Paracentrotus lividus populations in the Eastern Mediterranean-Result of climate change? Sci. Rep., 5, 13479.

Yeruham, E., Shpigel, M., Abelson, A., Rilov, G., 2020. Ocean warming and tropical invaders erode the fitness of a key herbivore. Ecology, 101, e02925.

Zabala, M., Ballesteros, E., 1989. Surface-dependent strategies and energy flux in benthic marine communities or, why corals do not exist in the Mediterranean. Sci. Mar., 53, 1-15.

Zenetos, A., Galanidi, M., 2020. Mediterranean non indigenous species at the start of the 2020s: Recent changes. Mar. Biodiv. Rec., 13, 10.

Zenetos, A., Gofas, S., Morri, C., Rosso, A., Violanti, D., García Raso, J.E., et al., 2012. Alien species in the Mediterranean Sea by 2012. A contribution to the application of European Union's Marine Strategy Framework Directive (MSFD). Part 2. Introduction trends and pathways. Medit. Mar. Sci., 13, 328-352.

Zhang, M., Xu, L., 2020. Transport of micro- and nanoplastics in the environment: Trojan-Horse effect for organic contaminants. Critical Rev. Environ. Sci. Technol., doi: 10.1080/10643389.2020.1845531.

Zogaris, S., De Maddalena, A., 2014. Sharks, blast fishing and shifting baselines: insights from Hass's 1942 Aegean expedition. Cah. Biol. Mar., 55, 305-313.

Žuljević, A., Peters, A.F., Nikolić, V., Antolić, B., Despalatović, M., Cvitković, I., et al., 2016. The Mediterranean deep-water kelp Laminaria rodriguezii is an endangered species in the Adriatic Sea. Mar. Biol., 163, 69. 
Zunino, S., Melaku Canu, D., Marangon, F., Troiano, S., 2020. Cultural ecosystem services provided by coralligenous assemblages and Posidonia oceanica in the Italian seas. Front. Mar. Sci., 6, 823.

Zupan, M., Fragkopoulou, E., Claudet, J., Erzini, K., Horta e Costa, B., Gonçalves, E.J., $2018 b$. Marine partially protected areas: drivers of ecological effectiveness. Front. Ecol. Environ., $16,381-387$. 


\section{Figure captions}

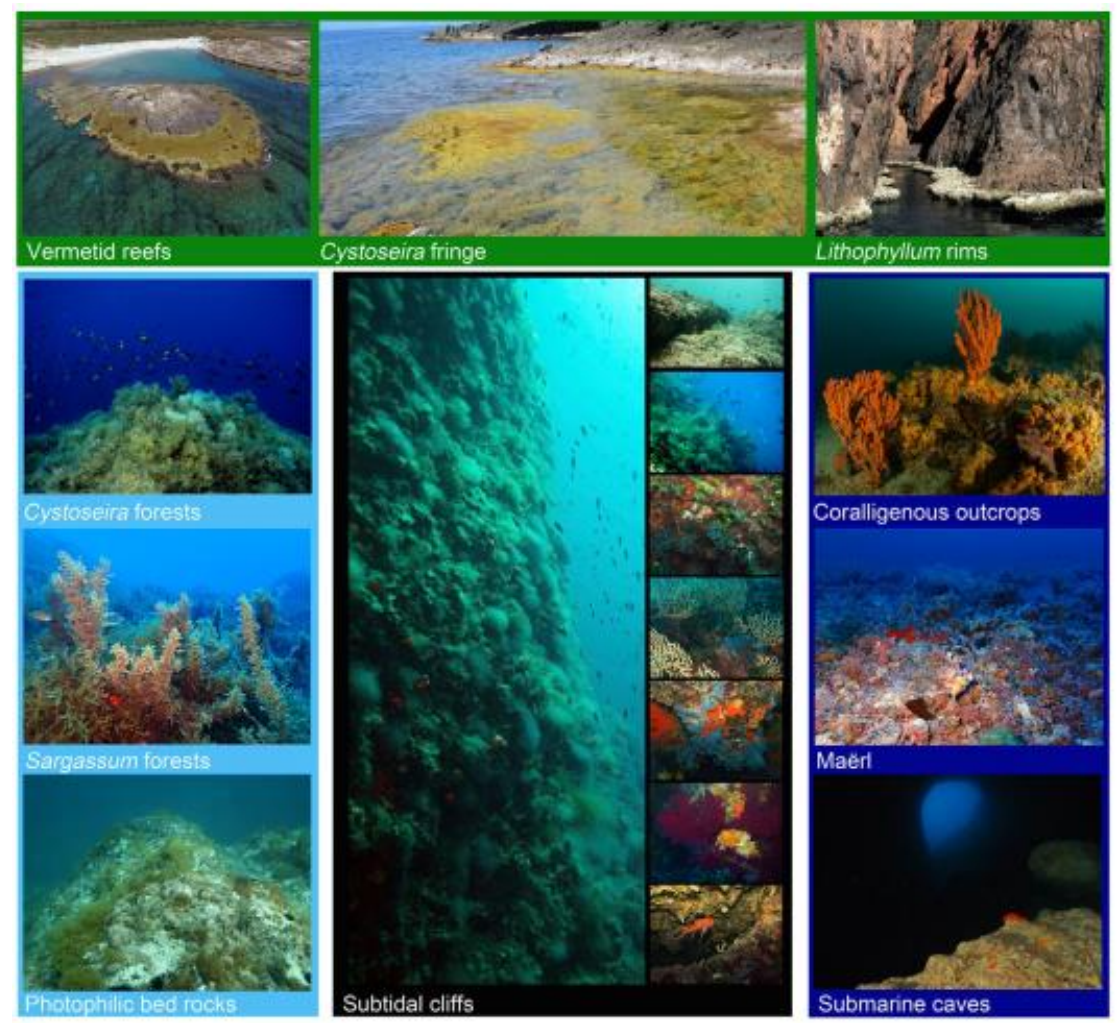

Figure 1. Examples of Mediterranean rocky habitats. Mediolittoral/upper infralittoral (green contour): vermetid reefs ${ }^{1}$ (Levantine, Israel); Cystoseira fringe ${ }^{2}$ (NW Mediterranean, Italy); Lithophyllum rims $^{3}$ (NW Mediterranean, France). Infralittoral (light blue contour): Cystoseira forests $^{4}$ (NW Mediterranean, France); Sargassum forests ${ }^{5}$ (NW Mediterranean, Spain); photophilic bed $\operatorname{rocks}^{6}$ (Adriatic Sea, Italy). Circalittoral/sciaphilic (dark blue contour): coralligenous outcrops ${ }^{7}$ (Aegean Sea, Greece); Maërl ${ }^{8}$ (NW Mediterranean, Spain); submarine caves ${ }^{9}$ (Ionian Sea, Italy). Sublittoral cliffs ${ }^{10}$ (black contour, Adriatic Sea, Croatia): the sequence of panels showed the gradient in benthic assemblages from 2-3 m until $60 \mathrm{~m}$ depth on the rocky wall. Photo credits: G.

Rilov $^{1}$, L. Benedetti-Cecchi ${ }^{2}$, E. Ballesteros ${ }^{3,4,5,8}$, G. Guarnieri6 ${ }^{6,9}$, Th. Dailianis ${ }^{7}$, G. Guarnieri and S. Bevilacqua $^{10}$. 

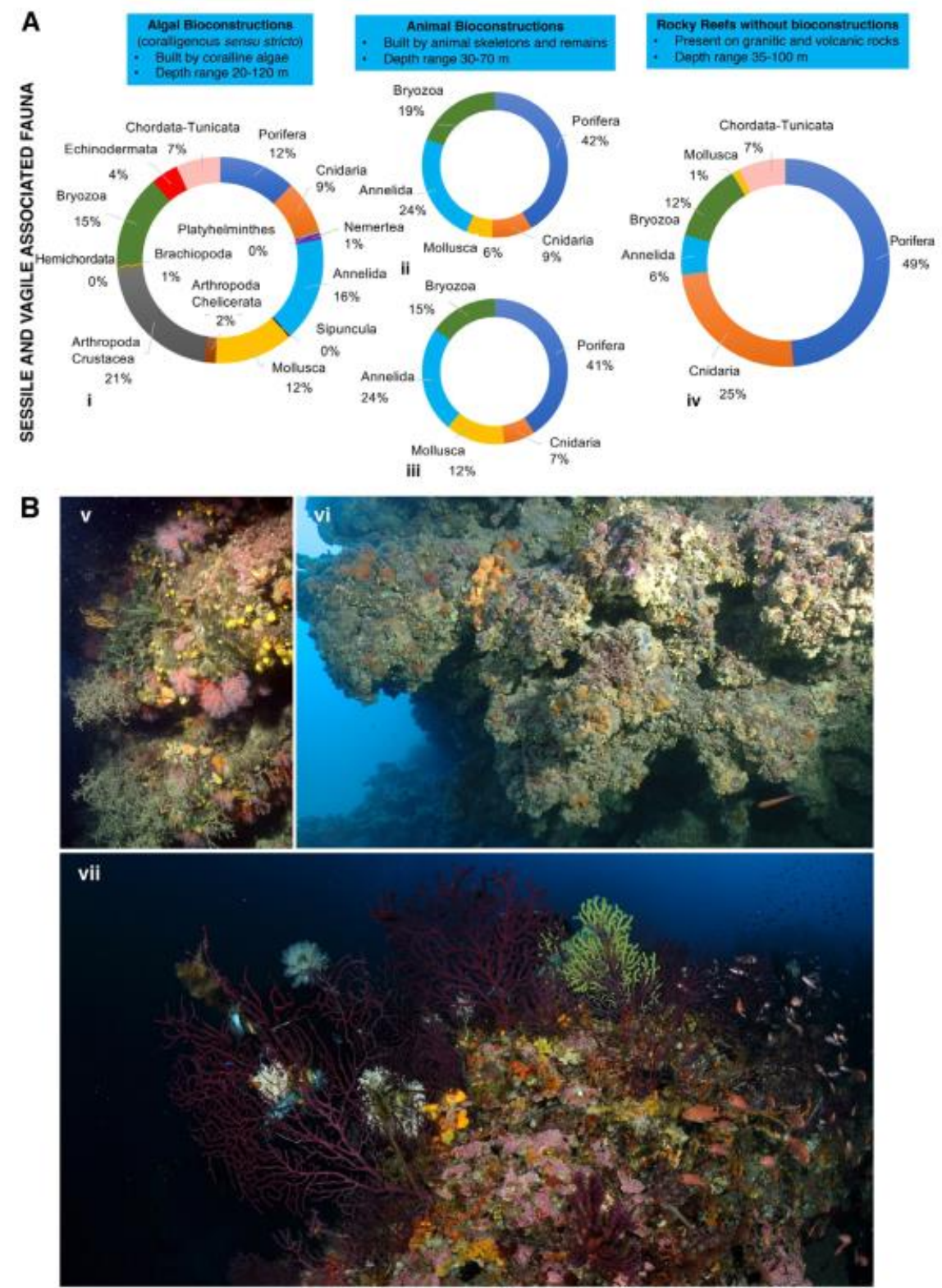

Figure 2. (A) Percentage abundance of sessile and vagile taxa associated with bioconstructions dominated by macroalgae (i), invertebrates (ii, iii) and rocky reefs without bioconstruction (iv). Data extracted from: i) Ballesteros (2006); ii) Cardone et al. (2020); iii) Corriero et al. (2019); iv) Canessa et al. (2020). (B) coralligenous sensu stricto (v); animal bioconstruction dominated by Neopycnodonte cochlear (vi), granitic rocky reef (vii). Photo credits: C. Cerrano (v, vii), G. Corriero (vi). 


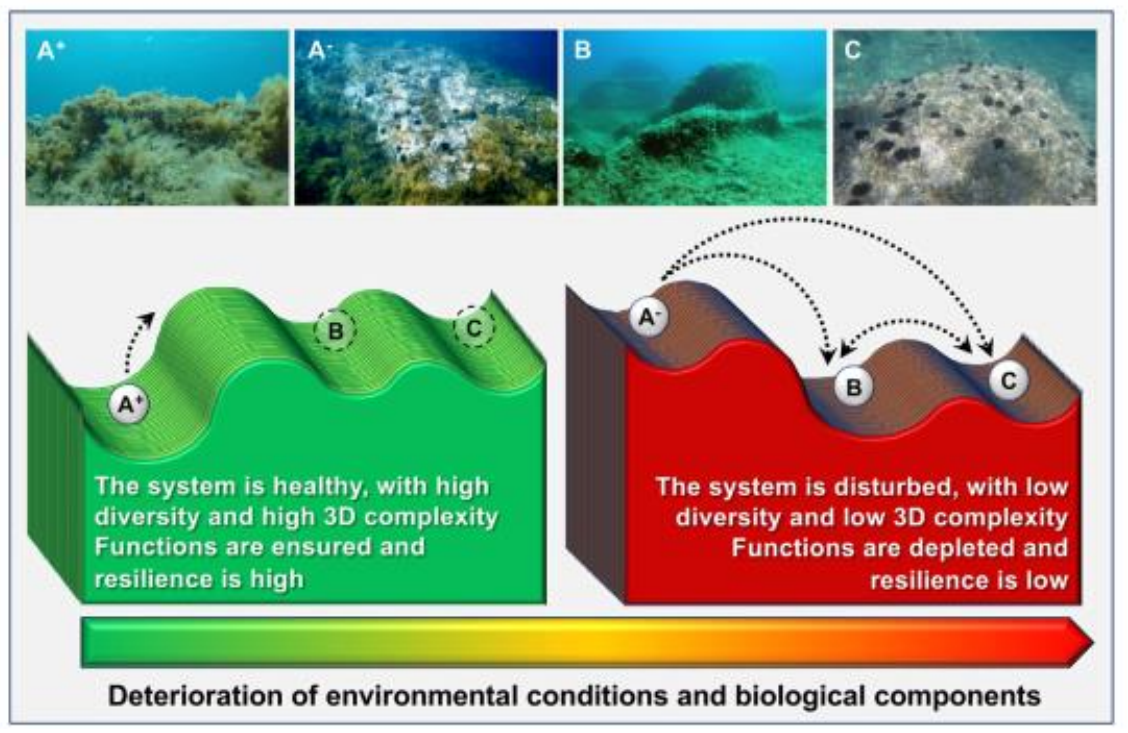

Figure 3. Conceptual representation of regime shifts from Mediterranean algal forests towards barren grounds and turf-dominated assemblages. In good environmental conditions, the system is dominated by habitat-forming macroalgae (e.g., Cystoseira s.l.) $\left(\mathrm{A}^{+}\right)$. Resilience is high, and pulse disturbances, if occurring, are unable to trigger a critical transition, with perturbations of the state (dotted black lines) being rapidly absorbed. As human-driven deterioration of environmental conditions increase and cause chronic disturbance (red landscape), the system approximates to a tipping point. Diversity decreases, the trophic network starts to disrupt and the recovery potential slows down, increasing system fragility $\left(\mathrm{A}^{-}\right)$. In such a situation, pulse disturbance events (e.g., organic enrichment, herbivore outbreaks) could drive the system to shift toward algal turfs (B) or barren grounds (C). Depending on changing conditions, the system could exhibit a 'flickering' behaviour between alternate stable states B and C. However, the return to the original state $\left(\mathrm{A}^{+}\right)$is difficult to happen if not over a long period, unless a substantial improvement of environmental conditions occurs and active restoration interventions are carried out to help the system to recover. 


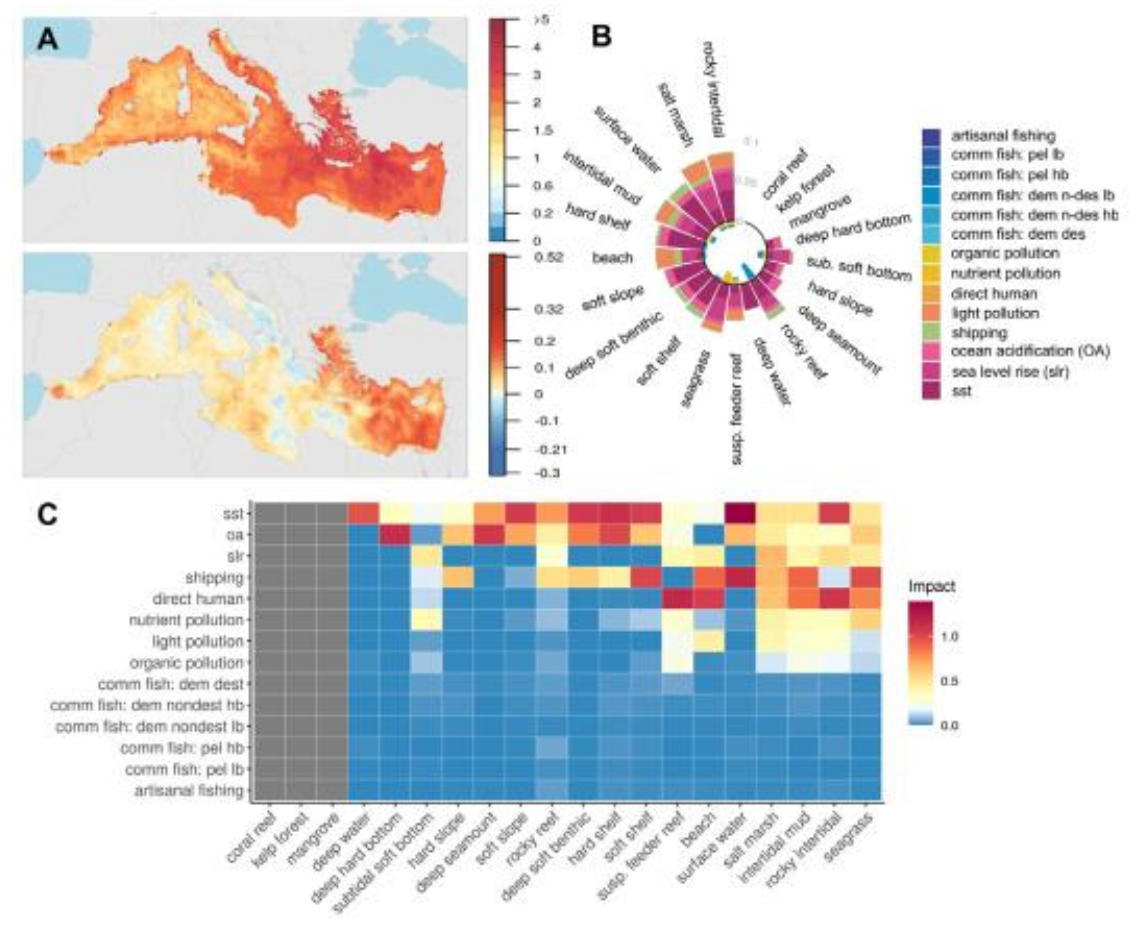

Figure 4. (A) Cumulative human impacts (up to 2013, top panel), and annual change in cumulative human impacts (bottom panel) estimated using a linear regression model from 2003 to 2013 for each raster cell (white cells did not have a statistically significant trend, i.e., $p>0.05$ ), scale values reflect min and max raster values $(-0.3$ and 0.52$)$ and $99.999^{\text {th }}$ quantile values $(-0.21$ and 0.32$) .(B)$ Annual change in all 14 impacts comprising the cumulative impacts for each Mediterranean marine ecosystem, with outer bars above zero indicating increasing impacts and inner bars below zero indicate decreasing impacts. (C) Cumulative impacts on ecosystems for the most recent year for which data are available (2013, bottom panel). Data from Halpern et al. (2019). Note that here 'rocky reef' refers to infralittoral and circalittoral reefs, 'rocky intertidal' to mediolittoral rocky reefs, and 'suspension feeder reef' to mediolittoral bioconstructions (e.g., vermetid reefs). 


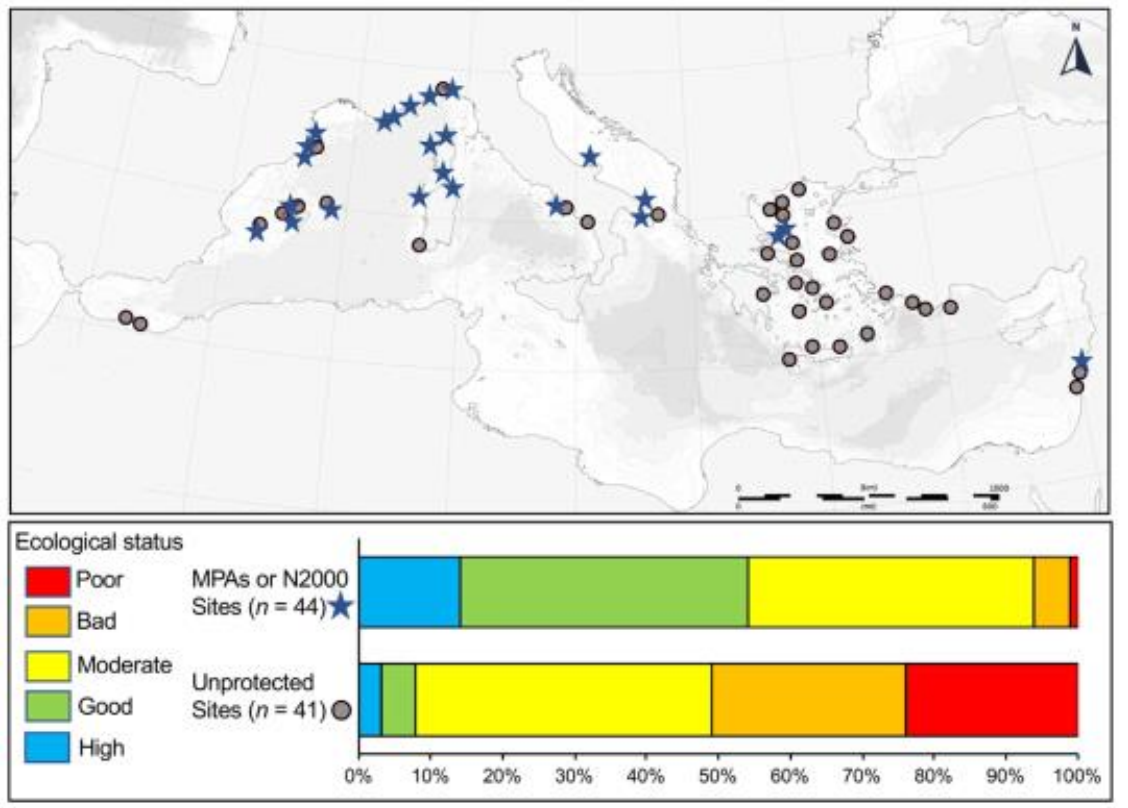

Figure 5. Ecological status of infralittoral rocky reefs in several sites across the Mediterranean Sea $(n=85)$. Ecological status is based on the Ecosystem Based Quality Index for rocky reefs (reefEBQI; Thibaut et al., 2017). The percentage of sites falling in different categories of reef-EBQI are reported separately for protected/regulated (MPAs and/or regulated Natura 2000 sites) and unprotected (including unregulated Natura 2000 sites) sites. Data from Bevilacqua et al. (2020).

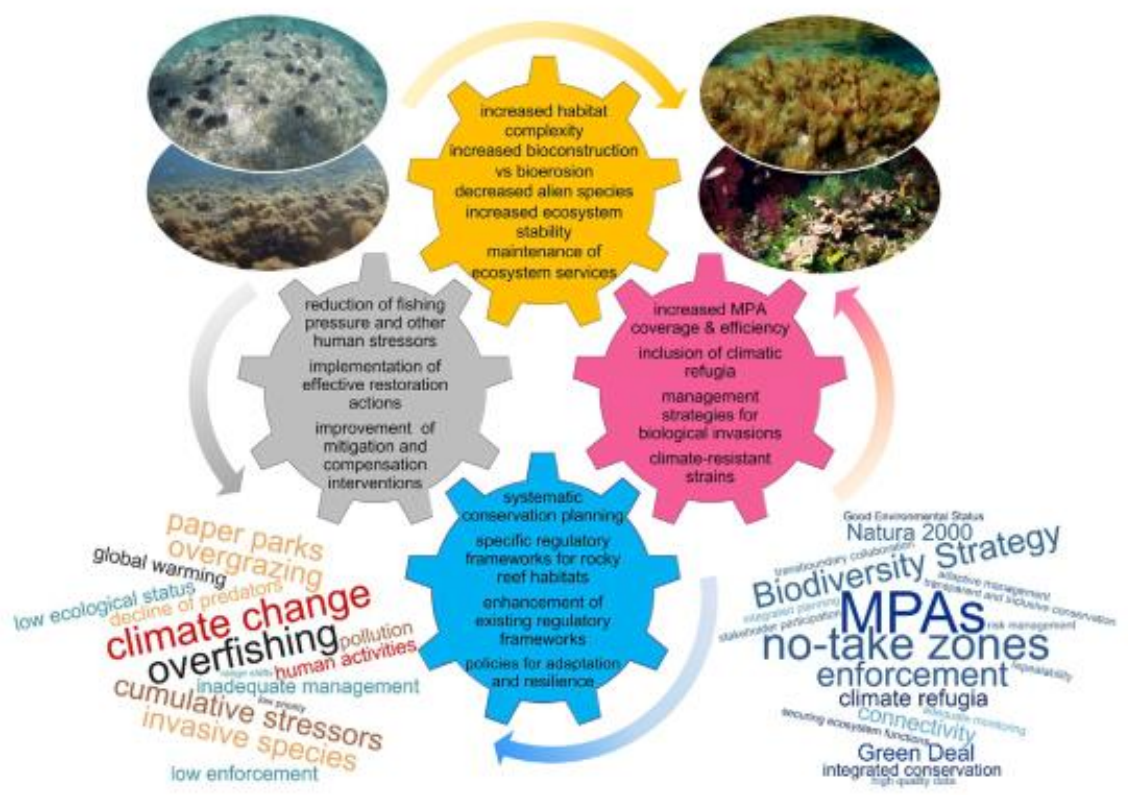

Figure 6. Improvements of management policies and conservation strategies are needed to decelerate or even reverse the declining trend on the ecological status of Mediterranean rocky reef ecosystems. 